\title{
Suppression of Arctic Sea Ice Growth in the Eurasian-Pacific Seas by Winter Clouds and Snowfallo
}

\author{
Won-Il Lim, ${ }^{a}$ Hyo-Seok PARK, ${ }^{\mathrm{b}}$ Andrew L. Stewart ${ }^{\mathrm{c}}$ And Kyong-Hwan SeO ${ }^{\mathrm{a}}$ \\ ${ }^{\text {a }}$ Department of Atmospheric Sciences, Pusan National University, Busan, South Korea \\ ${ }^{\mathrm{b}}$ Department of Ocean Science and Technology, Hanyang University, Ansan, South Korea \\ ${ }^{\mathrm{c}}$ Department of Atmospheric and Oceanic Sciences, University of California, Los Angeles, Los Angeles, California
}

(Manuscript received 9 April 2021, in final form 27 October 2021)

\begin{abstract}
The ongoing Arctic warming has been pronounced in winter and has been associated with an increase in downward longwave radiation. While previous studies have demonstrated that poleward moisture flux into the Arctic strengthens downward longwave radiation, less attention has been given to the impact of the accompanying increase in snowfall. Here, utilizing state-of-the-art sea ice models, we show that typical winter snowfall (snow water equivalent) anomalies of around $1.0 \mathrm{~cm}$, accompanied by positive downward longwave radiation anomalies of $\sim 5 \mathrm{~W} \mathrm{~m}^{-2}$, can cause basinwide sea ice thinning by around $5 \mathrm{~cm}$ in the following spring over the Arctic seas in the Eurasian-Pacific seas. In extreme cases, this is followed by a shrinking of summer ice extent. In the winter of 2016/17, anomalously strong warm, moist air transport combined with $\sim 2.5-\mathrm{cm}$ increase in snowfall (snow water equivalent) decreased spring ice thickness by $\sim 10 \mathrm{~cm}$ and decreased the following summer sea ice extent by $5 \%-30 \%$. This study suggests that small changes in the pattern and volume of winter snowfall can strongly impact the sea ice thickness and extent in the following seasons.
\end{abstract}

KEYWORDS: Arctic; Sea ice; Atmosphere-ocean interaction; Snowfall

\section{Introduction}

The multidecadal retreat in Arctic sea ice has been superposed upon pronounced interannual variability, which has motivated efforts to understand year-to-variability in the winter sea ice growth season (Ricker et al. 2017; Stroeve et al. 2018; Petty et al. 2018a). For example, previous studies have shown that the initial sea ice thickness in late autumn-early winter preconditions the heat conductivity of the sea ice, and thereby strongly influences sea ice growth through the winter (Maykut 1978; Stroeve et al. 2018; Petty et al. 2018a). Autumn and winter variations in poleward moisture transport also modulate winter sea ice growth via changes in downward longwave radiation (Park et al. 2015; Woods and Caballero 2016; Hegyi and Taylor 2018) and are predicted to become increasingly influential during the coming decades (Petty et al. 2018a).

This study considers an additional direct effect of interannual variations in moisture transport into the Arctic on sea ice growth: increased winter snowfall. Over the Eurasian-Pacific seas, such as the Laptev, East Siberian, and Chukchi Seas, snowfall makes up more than $60 \%$ of the annual precipitation (Bintanja and Andry 2017). Because the thermal conductivity of snow is about 7 times lower than ice, it may be expected to insulate the sea ice in these sectors from the atmosphere, and thus suppress winter ice growth (Sturm et al. 2002; Persson et al. 2017). This insulation should be particularly effective in the Eurasian-Pacific seas, where relatively thin first-year ice is

Supplemental information related to this paper is available at the Journals Online website: https://doi.org/10.1175/JCLI-D-210282.s1

Corresponding author: Hyo-Seok Park, hspark1@gmail.com becoming increasingly dominant (Petty et al. 2018b). This raises the possibility that a small increase in snowfall associated with atmospheric moisture flux convergence may suppress sea ice growth throughout the winter. While previous studies have pointed out the close linkage between poleward moisture flux into the Arctic and increased downward longwave radiation (Park et al. 2015; Woods and Caballero 2016; Hegyi and Taylor 2018), relatively little attention has been given to the accompanying increase in snowfall and its potential suppression of sea ice growth.

In this study, the impact of winter snowfall on the wintertime seasonal cycle of sea ice thickness is investigated using a state-of-the-art sea ice model, the Los Alamos sea ice model CICE version 6.0 (hereafter CICE6) (Craig et al. 2018). The model is forced by an atmospheric state reconstructed from the European Center for Medium-Range Weather Forecasts reanalysis version 5 (ERA5) dataset (Hersbach et al. 2020). ERA-Interim (an interim version of ERA5; Dee et al. 2011) has shown the best performance in simulating the Arctic surface radiative fluxes (Zib et al. 2012) among various reanalysis products. ERA-Interim also exhibits good performance in simulating total precipitation in the Arctic (Lindsay et al. 2014), although rainfall (liquid precipitation) is about 5 times more frequent than in satellite observations (Boisvert et al. 2018). By performing idealized perturbations experiments using CICE6, we demonstrate that typical positive winter snowfall anomalies of $1.0 \mathrm{~cm}$ in snow water equivalent (SWE), which is approximately $3.0 \mathrm{~cm}$ of snow depth, averaged over the Eurasian-Pacific seas $\left(69^{\circ}-90^{\circ} \mathrm{N}, 60^{\circ}-240^{\circ} \mathrm{E}\right)$ suppress the sea ice growth in the winter and early spring and cause substantial ice thinning in the following late spring and summer. We further demonstrate that the snowfall-driven sea ice thinning is doubled by the accompanying strengthening of downward radiation and surface air warming/moistening. 


\section{Data and methods}

To assess the interannual variations of winter snowfall of ERA5, we examined the Japanese 55-year Reanalysis (JRA55) (Kobayashi et al. 2015), the Modern-Era Retrospective Analysis for Research and Applications version 2 (MERRA2) (Gelaro et al. 2017), and the Climate Forecast System Reanalysis (CFSR) (Saha et al. 2014). We use these four reanalysis products because they provide estimates of the atmospheric state beyond 2019, and because their performances in simulating the Arctic precipitation variability have been evaluated (Barrett et al. 2020). To validate the CICE6-simulated sea ice extent, we utilized the satellite-observed sea ice extent version 3 provided by the National Snow and Ice Data Center (NSIDC) (Fetterer et al. 2017). To systematically evaluate our model's simulated sea ice thickness and snow depth, we examined the coupled Pan-Arctic Ice-Ocean Modeling and Assimilation System (PIOMAS; Zhang and Rothrock 2003) and the NASA Eulerian Snow on Sea Ice Model (NESOSIM; Petty et al. 2018b). PIOMAS spans 1979 to the present; NESOSIM spans 2000-15. The February-March average Arctic sea ice thickness simulated by PIOMAS is similar to that derived from satellite observations (Collow et al. 2015), although the satellite-observed Arctic sea ice thickness has large uncertainty (Lindsay and Schweiger 2015). PIOMAS evolves the snow depth over sea ice via a snow thickness distribution equation that conserves snow mass using a constant snow density (Flato and Hibler 1995). NESOSIM uses the median snowfall from multiple reanalysis products (ERAInterim, MERRA-2, JRA-55, and the Arctic System Reanalysis version 1; Bromwich et al. 2016) to drive its ocean-sea ice model. NESOSIM uses snow depth climatology of Warren (1999), which is scaled by near-surface temperature, as an initial condition for each September. Unlike PIOMAS, in NESOSIM the snowmelt is not simulated and snow densification by wind is parameterized. The seasonal cycle and regional distribution of the NESOSIM snow depth match well with in situ station data (Petty et al. 2018b).

\section{a. Sea ice-slab-ocean model configuration}

To investigate the impact of snowfall on the seasonal ice thickness, we utilized a state-of-the-art model, the Los Alamos sea ice model CICE6 (Craig et al. 2018). The material and thermal characteristics of sea ice are represented using an elastic-anisotropic-plastic rheology (Wilchinsky and Feltham 2006; Tsamados et al. 2013) and using mushy layer thermodynamics (Feltham et al. 2006; Turner et al. 2013), respectively. The model has five ice categories with seven vertical layers and calculates energy fluxes between snow and each ice category. We use a displaced pole grid with $320 \times 384$ grid points, corresponding to a horizontal grid spacing of approximately $1^{\circ}$. Solar radiation within the sea ice and overlying snow cover is computed via the delta-Eddington method (Briegleb and Light 2007).

The sea ice model is coupled to a slab-ocean model to simplify the ocean dynamics. The mixed layer depth in the Arctic Ocean has a seasonal cycle, ranging from depths greater than $20 \mathrm{~m}$ in winter to depths of $5-30 \mathrm{~m}$ in summer (Cole et al.
2014; Peralta-Ferriz and Woodgate 2015). In this study, we imposed a spatially uniform and seasonally varying mixed layer depth based on the CMCC Global Ocean Physical Reanalysis System (C-GLORS) version 5 (Storto and Masina 2016), a global ocean reanalysis combined with in situ and satellite observations. We reduced the C-GLORS mixed layer depth in summer by $10 \%$ to better track hydrographic observations (see supplemental Fig. 1).

Over the sub-Arctic seas, where the sea ice concentration (SIC) is generally less than $15 \%$ throughout the year (since year 2000), we restored the sea surface temperatures to monthly historical SSTs. The rationale for this restoring is that the marginal seas, especially the Nordic seas surface temperatures, have continuously increased over the last decades (supplemental Fig. 2), and the slab-ocean model of CICE6 underestimates this warming trend if the model is integrated without the restoring. Other than imposing the SSTs in the marginal seas, we used default parameter values for the slab ocean, with zero "deep ocean heat flux" $(q d p=0)$. The sea surface salinity (SSS) is set to 31 PSU throughout the year, which is close to the observed salinity over the Arctic Ocean (Steele et al. 2001). Thus, the modeled sea surface salinity does not respond to changes in ice growth and melt.

\section{1) HistoricAl Simulation (Hist)}

Our simulations run for 40 years, from 1979 to 2018, during which satellite-observed Arctic sea ice concentration and reanalysis data are available. For the atmospheric forcing of CICE6, we utilized ERA5 (Hersbach et al. 2020). Specifically, we imposed 6-hourly meteorological fields (temperature, specific humidity, and zonal and meridional winds), 6-hourly radiative fluxes (downward shortwave and longwave radiation at the surface), and 6-hourly precipitation (rainfall and snowfall) in each model grid cell. CICE6 was integrated over 80 years to "spin up," during which we repeated the 1979-88 atmospheric forcing eight times. The historical simulations were then initialized from the end of this spinup simulation, starting from year 1979.

\section{2) CLIMATOLOGICAL WINTER SNOWFALL EXPERIMENT (CSNOW)}

To identify the impact of anomalous snowfall on Arctic sea ice growth on interannual time scales, we configured a CICE6 simulation in which the winter (November-March) snowfall in each year was replaced by climatological snowfall. Specifically, each year's November of historical simulation (Hist) was used for the initial condition of the climatological winter snowfall experiment (cSnow), in which the winter (NovemberMarch) snowfall was replaced by climatological snowfall. Each cSnow experiment was integrated for 12 months, starting from November of the year in which the experiment was initiated and ending in October of the following year. Because the Arctic winter snowfall shows an increasing trend in ERA5, accumulated snowfalls in recent years are substantially larger than in the 1980 s to 1990 s. To remove this long-term trend, which is possibly unreliable, the snowfall climatology is defined via the linear regression line of the winter snowfall at each grid 
point. Therefore, the snowfall anomalies correspond to interannual variability. We then compared winter ice thicknesses between this simulation (cSnow) and our historical simulation (Hist) to quantify the impact of anomalous winter snowfall. Again, these idealized experiments were conducted until the following October to identify the impact of the winter snowfall on the subsequent spring and summer sea ice.

3) COMBINATION OF PARAMETERS: THE NET EFFECT OF INCREASED SNOWFALL AND ACCOMPANYING ATMOSPHERIC FORCINGS (CSNOW + CDLW + CT + Cq)

This experiment is designed to identify the combined effects of snowfall and downward longwave radiation, which is also accompanied by surface air warming and moistening. Similar to experiment cSnow, we configured CICE6 with historical atmospheric forcing, but replaced the downward longwave radiation, surface air temperature, surface specific humidity, and snowfall with their climatological counterparts from November to March in each year. Specifically, for each year (from 1979/80 to 2017/18) we initiated an experiment (cSnow + cDLW + cT + cq) using the model state at the start of November in our historical simulation (Hist). In this experiment we replaced the winter (November-March) downward longwave radiation, surface air temperature, surface specific humidity, and snowfall by their respective climatological means. We integrated each experiment until the end of October in the following year.

\section{b. CESM2: Sea ice-full-ocean model simulations}

To verify the robustness of CICE6-slab-ocean model simulations, we also performed an ocean-ice coupled model experiment using the Community Earth System Model version 2 (CESM2) (Danabasoglu et al. 2020). The ocean and ice components of CESM2 are the second version of the Parallel Ocean Program (POP2) (Smith et al. 2010) and Community Ice Code version 5 (CICE5) (Hunke et al. 2015). POP2 has a displaced North Pole horizontal grid with gx1v7 grid resolution, which is the same as the CICE6-slab-ocean model used in this study, and 60 vertical levels whose thicknesses monotonically increase from $10 \mathrm{~m}$ in the upper ocean to $250 \mathrm{~m}$ in the deep ocean. The ocean-ice coupled model simulation is forced by a 3-hourly atmospheric state (temperature, sea level pressure, humidity, winds), radiative fluxes (downward longwave and shortwave), and precipitation from JRA55-do (Tsujino et al. 2018), a surface dataset designed for driving ocean-sea ice models. Specifically, surface fields of JRA-55 are adjusted using satellite observations and other reanalysis data to better simulate sea surface temperatures and sea ice in the polar regions (Tsujino et al. 2018). The historical CESM2 ocean-sea ice simulations driven by JRA55-do comprises one of the standard component sets of CESM2.

We performed additional historical CESM2 ocean-sea ice simulations using ERA5 forcing, which is not listed as a standard component set of CESM2. CESM2 ocean-sea ice forced by ERA5 simulates excessively small summer sea ice extent. To reduce this bias, the base ice and snow tuning parameters are increased to 40 and 15 , respectively ( $\mathrm{r} \_$ice $=40$ and r_snw = 15) when ERA5 data are used for driving CESM2. Increasing the ice and snow tuning parameters (r_ice and r_snw) increases the surface albedo over sea ice and snow, respectively, and decreases the transmissivity into sea ice layers (Briegleb and Light 2007).

\section{1) HistoricAl Simulation (Hist)}

For CESM2 with JRA55-do forcing, we integrated the model for 61 years from 1958 to 2018, then used the first 21 years (from 1958 to 1978 ) as a spinup simulation and the remaining 40 years (from 1979 to 2018) as a historical simulation. For CESM2 with ERA5 forcing, the model was integrated over 20 years to spin up, during which we repeated the 1979-88 atmospheric forcing two times. The historical simulations were then initialized from the end of this spinup simulation, starting from year 1979. In both model configurations (JRA55-do and ERA5 forcings), four different ensemble historical runs were simulated by using four different initial conditions (perturbations in high-latitude SSTs) in January 1979.

\section{2) COMBINATION OF PARAMETERS: THE NET EFFECT OF INCREASED SNOWFALL AND ACCOMPANYING ATMO- SPHERIC FORCINGS (CSNOW + CDLW + CT + Cq)}

To identify the combined effects of snowfall and downward longwave radiation, which is also accompanied by surface air warming and moistening, we followed a similar procedure as in our CICE6-slab-ocean model experiments. We configured CESM2 with historical atmospheric forcing, but replaced the downward longwave radiation, surface air temperature, surface specific humidity, and snowfall with their climatological counterparts from November to March for 1998/99 and 2016/17. We selected these two specific winters, 1998/99 and 2016/17, because the four reanalysis products consistently indicate that the snowfall anomaly averaged over the EurasianPacific seas was smallest in 1998/99 and largest in 2016/17. Specifically, we conducted two experiments (cSnow + cDLW + $\mathrm{cT}+\mathrm{cq}$ ) starting from the state of the historical simulation (Hist) at the beginning of November 1998 and November 2016, respectively, in which the winter (November-March) downward longwave radiation, surface air temperature, surface specific humidity, and snowfall were replaced by climatological means. We integrated each experiment until the subsequent Octobers (i.e., until October 1999 and October 2017, respectively). For each of these experiments, we ran an ensemble of four simulations with SST perturbations. Each ensemble member shows very similar sea ice thickness and concentration anomalies throughout the season, probably because atmospheric boundary conditions are prescribed and the model is integrated only for 12 months.

\section{c. A simple one-dimensional sea ice model with snow}

The insulating effect of snow may be understood with the aid of a one-dimensional (1D) conceptual model of the sea ice/snow heat budget. Assuming that the sea ice is composed of a single homogeneous layer of ice for simplicity, and that the sea ice temperature instantaneously equilibrates to the 
heat fluxes at its base and to the atmospheric conditions above the ice and snow, the heat balance at the ice-atmosphere interface can be written as

$$
F_{c}^{\uparrow}=F_{\mathrm{LW}}^{\uparrow}-F_{\mathrm{LW}}^{\downarrow}+\mathrm{SHF}^{\uparrow}+\mathrm{LHF}^{\uparrow} .
$$

Here, $F_{\mathrm{LW}}^{\uparrow}$ and $F_{\mathrm{LW}}^{\downarrow}$ denote upward and downward longwave radiative fluxes, respectively, and $\mathrm{SHF}^{\uparrow}$ and $\mathrm{LHF}^{\uparrow}$ denote upward sensible and latent heat fluxes, respectively. We have neglected net shortwave radiation $F_{\mathrm{SW}}^{\downarrow}+F_{\mathrm{SW}}^{\uparrow}$, which is much weaker than other heat fluxes in winter. Increased snowfall suppresses the ice growth by reducing the upward conductive heat flux $\left(F_{c}^{\uparrow}\right)$, leading to a lower snow surface temperature and decreased sensible heat flux $\left(\mathrm{SHF}^{\uparrow}\right)$ and upward longwave radiation $\left(F_{\mathrm{LW}}^{\uparrow}\right)$.

To aid conceptual understanding of snow insulator effect on sea ice thickness, we construct a minimal $1 \mathrm{D}$ column model of the Arctic snow/sea ice heat budget following Maykut (1982) and Petty et al. (2013), assuming a steady balance between upward conductive heat flux through the snow/ice layer and the net surface heat loss. Utilizing bulk formulas for sensible and latent heat fluxes, Eq. (1) can be rewritten as

$$
\begin{aligned}
F_{c}\left(T_{S}\right)^{\uparrow}= & \sigma T_{S}{ }^{4}-F_{\mathrm{LW}}^{\downarrow}+\rho_{a} c_{p} C_{D} \mathbf{U}\left(T_{S}-T_{a}\right) \\
& +\rho_{a} L_{S} C_{D} \mathbf{U}\left[q_{\mathrm{sat}}\left(T_{S}\right)-q_{a}\right],
\end{aligned}
$$

where $T_{S}$ and $T_{a}$ are snow-covered ice surface temperature and 2-m air temperature, respectively; $\mathbf{U}$ is wind speed at $10 \mathrm{~m} ; q_{a}$ is the specific air humidity at $2 \mathrm{~m}$ and $q_{\text {sat }}$ is the saturation specific humidity; $\sigma$ is Stefan-Boltzmann constant; and $C_{D}$ is turbulent transfer coefficient over sea ice.

Following Semtner (1976), we assume a linear temperature gradient through snow and sea ice, so the conductive heat flux $F_{c}\left(T_{S}\right)^{\uparrow}$ may be written as

$$
F_{c}\left(T_{S}\right)^{\uparrow}=\frac{k_{i} k_{s}\left(T_{f}-T_{S}\right)}{\left(k_{i} h_{S}+k_{S} h_{i}\right)} .
$$

Here $T_{f}$ is the freezing temperature of seawater, $h_{i}$ and $h_{s}$ are the thicknesses of ice and snow, respectively, and $k_{i}$ and $k_{s}$ are the thermal conductivities of ice and snow, respectively. Note that snow is an effective thermal insulator: $k_{s}$ is about 7 times smaller than $k_{i}$. In winter, sea ice grows by conducting heat upward from the bottom of the ice to the surface. Assuming that the ocean surface is at the freezing temperature, the freezing rate at the bottom of ice is simplified as

$$
\Phi_{h}=F_{c}^{\uparrow} /\left(\rho_{i} L_{f}\right)
$$

where $\rho_{i}$ is the density of ice and $L_{f}$ is latent heat of fusion. Here, we calculate $T_{S}$ and $F_{c}^{\uparrow}$ by solving Eqs. (2) and (3) with prescribed thicknesses of ice and snow, $h_{i}$ and $h_{s}$. Then, the ice growth rate $\Phi_{h}$ can be estimated from Eq. (4). Because there is no ice-ocean heat exchange, the ice growth rate of this simple model is entirely controlled by surface heat exchange.

In this study, we estimated typical values of these parameters from ERA5, specifically wintertime [November-March (NDJFM)] mean values, over the Arctic Ocean averaged from 1979 to 2018 . We used entire-Arctic (above $69^{\circ} \mathrm{N}$ ) averages and the Eurasian-Pacific sector $\left(69^{\circ}-90^{\circ} \mathrm{N}, 60^{\circ}-240^{\circ} \mathrm{E}\right)$ averages. The parameters we used for the Eurasian-Pacific sector of the Arctic Ocean are given in the appendix.

\section{Results}

\section{a. CICE6-slab-ocean model simulation of sea ice thickness and extent}

The satellite-observed August-September sea ice extent exhibits a rapid decline from 2001 to 2012, during which the sea ice extent has decreased by around 35\% (black line of Fig. 1a). Our CICE6 simulation with ERA5 atmospheric boundary conditions (Hist) simulates the observed variability and trend of summer sea ice extent well (blue line in Fig. 1a): the correlation coefficient between the August-September average sea ice extent in CICE6 and in observations is 0.95 , although there are substantial differences in regional sea ice concentrations between CICE6 and observations (supplemental Fig. 3). Specifically, the CICE6-simulated SICs are generally smaller than those derived from satellite observations (supplemental Fig. 3). This suggests that CICE6 simulates a larger marginal ice zone than typically exists in nature, and therefore that summer SICs are likely to be more sensitive to the recent increase in downward longwave radiation and surface air warming.

The seasonal cycles of sea ice extent and volume are also captured by CICE6 (Figs. 1c,d). Figure 1b shows that the CICE6-simulated interannual variations of the wintertime snow depth over sea ice, averaged over the entire Arctic, are significantly correlated with those of the coupled PIOMAS (Zhang and Rothrock 2003) (correlation coefficient is 0.73) and NESOSIM (Petty et al. 2018b) (correlation coefficient is 0.78). However, the mean snow depths and the amplitudes of interannual variability simulated by PIOMAS and NESOSIM are about $30 \%$ larger than those of CICE6. This reduced sea ice coverage implies that CICE6 receives less snowfall in September, which is consistent with the thinner snow depth in CICE6 than PIOMAS. Reconstruction of snow depth over Arctic sea ice is challenging because in situ observations of snow on sea ice have been sparse and methods of retrieving snow depth from satellite measurements have only recently been developed (Kwok et al. 2020). Moreover, validating the snow depth over the eastern Arctic is more difficult than other regions (Blanchard-Wrigglesworth et al. 2018) because of sparse observations. CICE6 includes more sophisticated schemes for snow sinks than PIOMAS and NESOSIM, such as snow lost during ridging (Roberts et al. 2019), snow-ice formation, and sublimation (Pomeroy et al. 1997), which could partly explain the relatively thin snow depth. However, the snow sinks associated with snow-ice formation and sublimation are an order of magnitude smaller than accumulation and melting (Webster et al. 2021). While September snow is almost entirely melted away in CICE6, snow in PIOMAS persists over perennial sea ice (supplemental Fig. 3). Also, September sea ice concentrations in CICE6 are smaller than those of derived from satellite observations (supplemental 

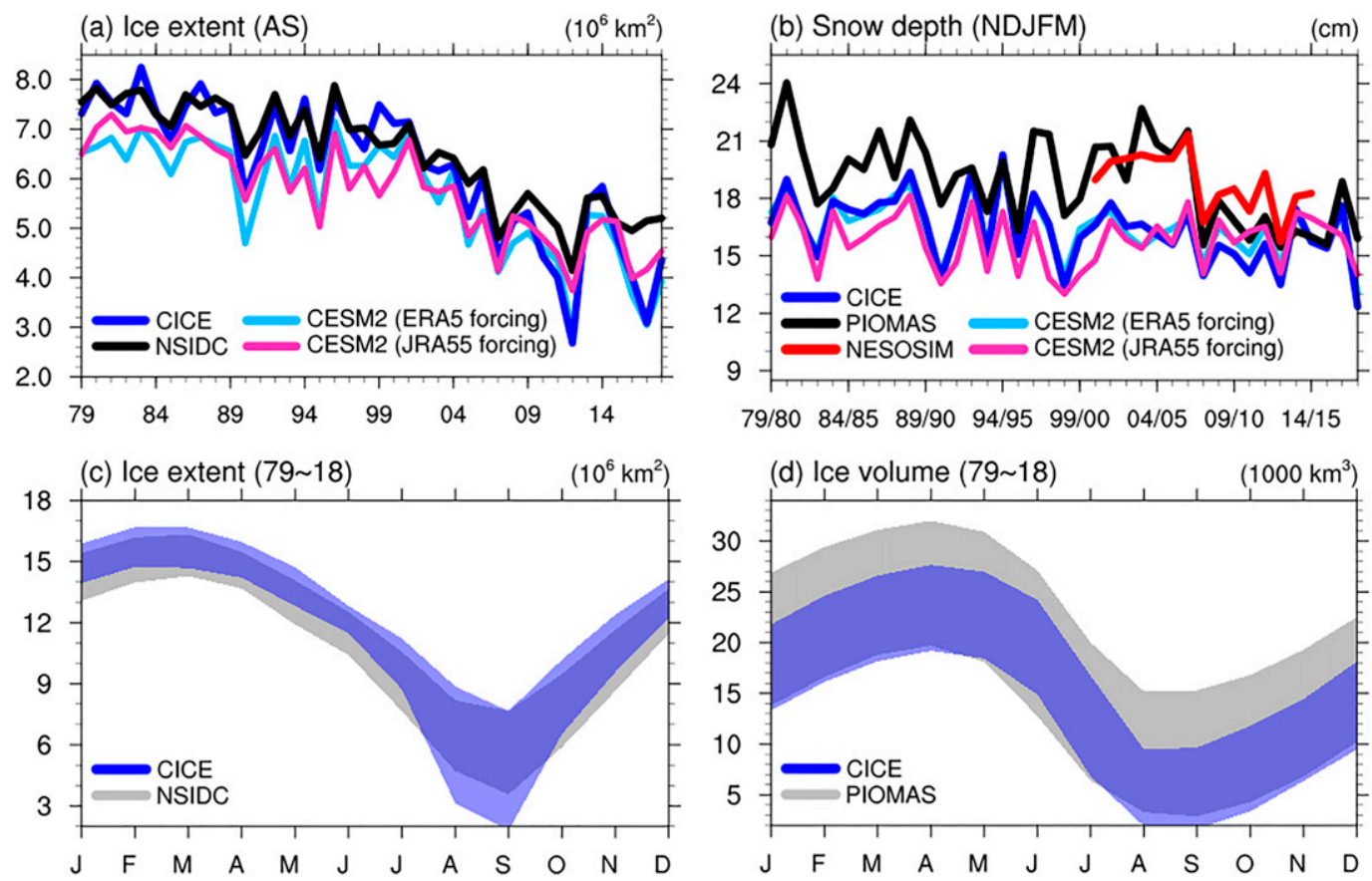

FIG. 1. Sea ice model simulation vs observations. The year-to-year variations of (a) late summer (August-September) Arctic sea ice extent simulated by our CICE6-slab-ocean model forced by ERA5 (blue), CESM2 forced by ERA5 (sky blue) and by JRA-55 (magenta), and from NSIDC observations (black), and (b) the wintertime (NDJFM) mean snow depth, averaged over the entire Arctic, simulated by our CICE6-slab-ocean model forced by ERA5 (blue), CESM2 forced by ERA5 (sky blue) and by JRA-55 (magenta), from PIOMAS (black), and from NESOSIM (red). Also shown are the climatological mean seasonal (monthly) variations of (c) sea ice extent and (d) sea ice volume. In (c) and (d), blue shading indicates the minimum-to-maximum ranges of sea ice extent and volume simulated by our CICE6-slab-ocean model forced by ERA5, and gray shading indicates the minimum-to-maximum ranges of (c) NSIDC observed sea ice extent and (d) PIOMAS sea ice volume.

Fig. 3). This reduced sea ice coverage implies that CICE6 receives less snowfall in September, which is consistent with the thinner snow depth in CICE6 than PIOMAS. Note that PIOMAS directly assimilates the satellite-observed sea ice concentration.

\section{b. Snow depth and ice growth rate in winter}

To what extent is the wintertime sea ice growth controlled by snow? Snow is a relatively poor conductor of heat, compared with sea ice, because a substantial fraction of its volume is trapped air. In winter, the insulating effect of snow decreases the conductive heat flux $F_{c}^{\uparrow}$, through the sea ice and snow, and thus decreases the rate at which seawater freezes to the base of the sea ice.

In this study, we examined the basin-scale sea ice growth rate from November, during which the Arctic Ocean basin above is mostly covered by sea ice. Because the delayed freeze-up in recent decades has substantially decreased sea ice cover, it is difficult to quantify the basin-scale snowfall forcing on the first-year sea ice in October. Moreover, the sea ice growth rate is more closely related to the late summer sea ice thickness than to the atmospheric state in October (Petty et al. 2018a). A recent study (Stroeve et al. 2018) defined the wintertime Arctic sea ice growth as the difference between
November and April sea ice thickness. In our CICE6 simulations, the interannual variability of the ice growth rate from November to March is strongly correlated with snow depth in winter, when averaged over the entire Arctic (Fig. 2a). This is consistent with our expectation that the decreased conductivity of the sea ice/snow layer should suppress ice growth, but this high correlation is also contributed by the negative correlation between sea ice thickness and growth rate; that is, thin sea ice grows faster by energy exchange over young sea ice in the central Arctic (Maykut 1978; Stroeve et al. 2018).

It is important to note that the insulating effect of snow on sea ice is geographically dependent. Over the Atlantic sector of the Arctic, the accumulated winter snowfall often exceeds $25 \mathrm{~cm}$ (SWE) (Fig. 3a) and snow-ice formation is generally larger than $15 \mathrm{~cm}$ (SWE) (Fig. 3b). Anomalously large winter snowfall over the Atlantic seas tends to produce anomalously thick ice, rather than anomalously thin ice (Granskog et al. 2017; Merkouriadi et al. 2017, 2020). In this study, we focus on the snow effect on sea ice in the Eurasian-Pacific seas, where first-year sea ice is becoming increasingly dominant (Petty et al. 2018b) and the snow-ice formation is relatively small. Over the Eurasian-Pacific seas, the correlation coefficient between the areally averaged detrended snow depth and the detrended ice growth rate is -0.80 (Fig. 2b), indicating 
(a) Entire Arctic $\left(0^{\circ}-360^{\circ} \mathrm{E}\right)$

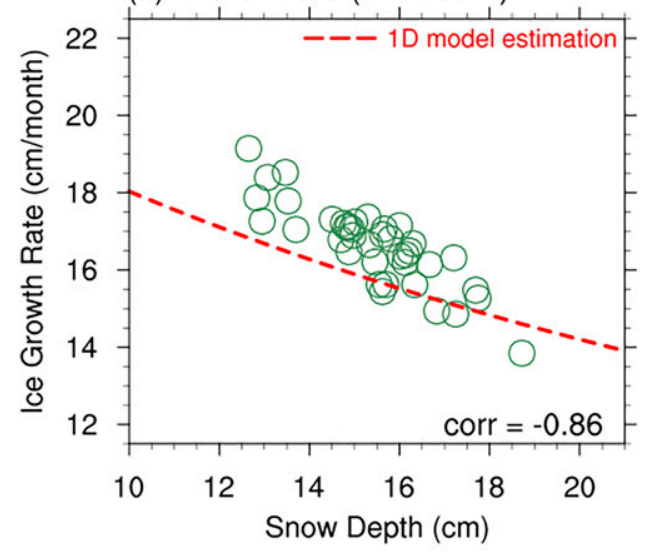

(c) Snow Depth

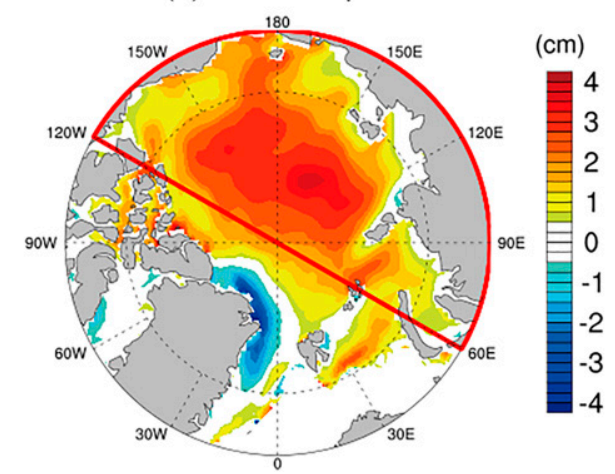

(b) Eurasian-Pacific $\left(60^{\circ}-240^{\circ} \mathrm{E}\right)$

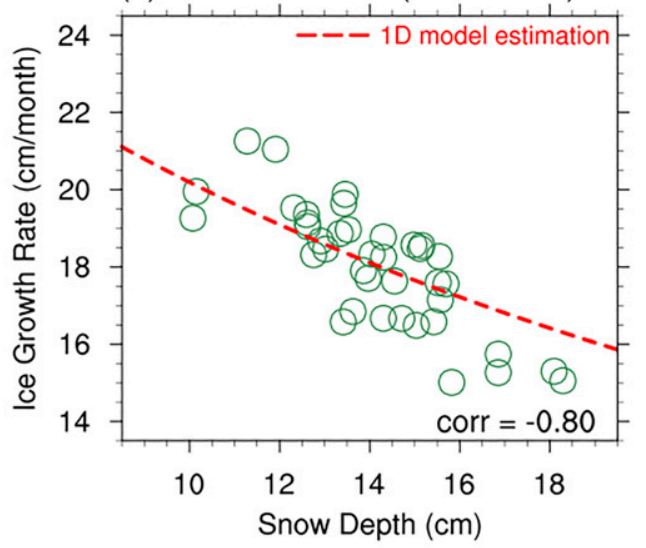

(d) Ice Growth Rate

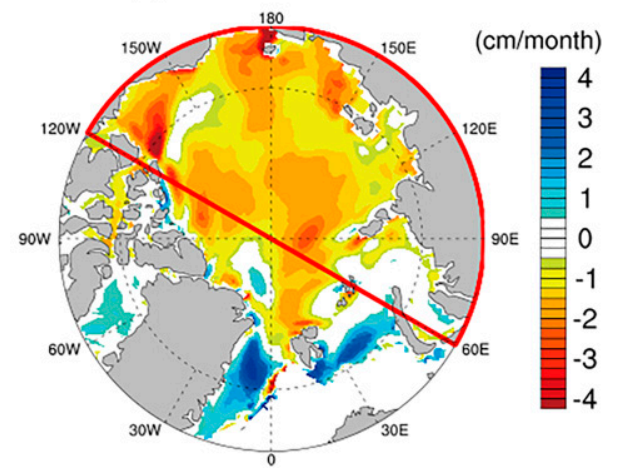

FIG. 2. Interannual relationship between snow depth and ice growth. Interannual variation of the wintertime (NDJFM) mean snow depth (abscissa; cm) and ice growth rate (ordinate; $\mathrm{cm} \mathrm{month}^{-1}$ ) from 1979/80 to 2017/18 averaged over (a) the entire Arctic and (b) the Eurasian-Pacific sector. The long-term trends of snow depth and ice growth rate have been removed. Red dashed lines in (a) and (b) are from the 1D model calculation with fixed downward longwave radiation and surface air temperature (see section 2 for details). Also shown is a regression map of the wintertime (c) snow depth and (d) ice growth rate anomalies associated with area-averaged snow depth anomalies (per one standard deviation anomaly) in the Eurasian-Pacific sector of the Arctic (red lines). Snow depth and sea ice thickness are from our CICE6-slab-ocean model with ERA5 historical forcing.

that the insulation effect of snow cover is probably dominant over the snow and ice formation.

This statistical relationship between the wintertime snow depth and ice growth is consistent with a simple $1 \mathrm{D}$ ice-snow model, indicated via red dotted lines in Figs. $2 \mathrm{a}$ and $2 \mathrm{~b}$. This $1 \mathrm{D}$ model indicates that increasing the wintertime mean snow depth from 13 to $18 \mathrm{~cm}$ can suppress the ice growth rate by $2 \mathrm{~cm} \mathrm{month}{ }^{-1}$, on average, or approximately $10 \mathrm{~cm}$ over a 5 -month period (NDJFM). Note that our 1D model assumes a constant sea ice thickness $(1.38 \mathrm{~m})$ and does not account for the seasonally increasing sea ice thickness from November to March. In reality, the sea ice growth may be expected to be more sensitive to snow depth anomalies in early winter than in late winter. The ice growth rate variations predicted by snow depth changes alone in this 1D model (red dotted lines) generally underestimate the sensitivity estimated from the interannual relationship between snow depth and ice growth rate (green scatterplots), both when averaged over the entire Arctic and over the Eurasian-Pacific seas (Figs. 2a,b). This suggests that there may be other factors that covary with snow depth (or snowfall) and suppress sea ice growth, as will be explored in the following sections.

To identify the spatial pattern of snow depth and ice growth rate on interannual time scales, we construct composite maps of snow depth and ice growth rate anomalies, as shown in Figs. $2 \mathrm{c}$ and $2 \mathrm{~d}$. In this study, we applied a simple linear regression analysis: the linear relationship between the winter snow depth anomaly and the ice growth from November to March is calculated. Specifically, the ice growth rate at each grid point is regressed on the winter (NDJFM) snow depth anomaly averaged over the Eurasian-Pacific seas, including the Laptev, East Siberian, and Chukchi Seas $\left(69^{\circ}-90^{\circ} \mathrm{N}\right.$, $\left.60^{\circ}-240^{\circ} \mathrm{E}\right)$. We then present the winter ice growth (in $\mathrm{cm}$ ) at each geographical location per one standard deviation (1 s.d.) of areally averaged (Eurasian-Pacific-sector-averaged) snow depth anomaly.

The regression map exhibits a basinwide increase in snow depth (Fig. 2c) and a basinwide decrease of the ice growth 


\section{Climatological mean}

\section{(a) Snowfall}

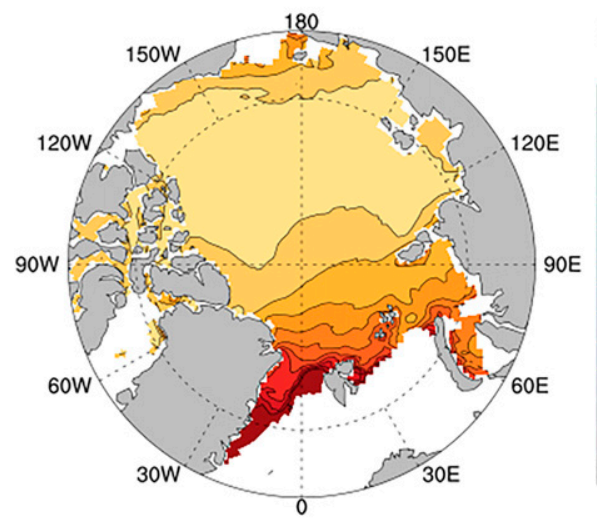

(b) Snow-Ice formation

(cm)

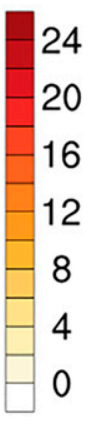

(cm)

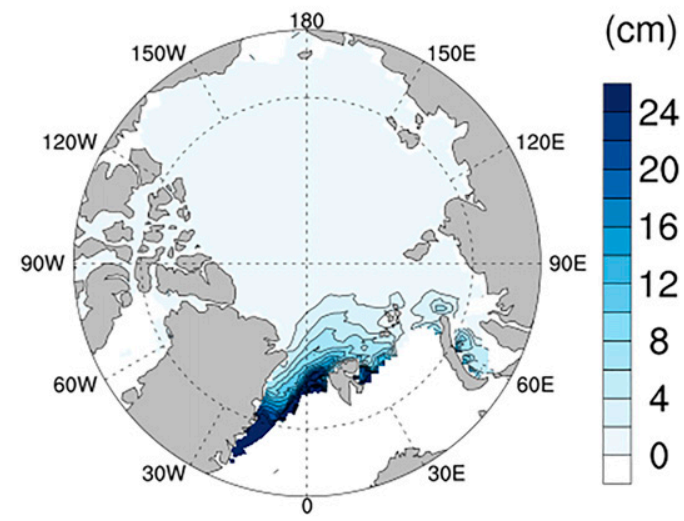

(c) Snowfall

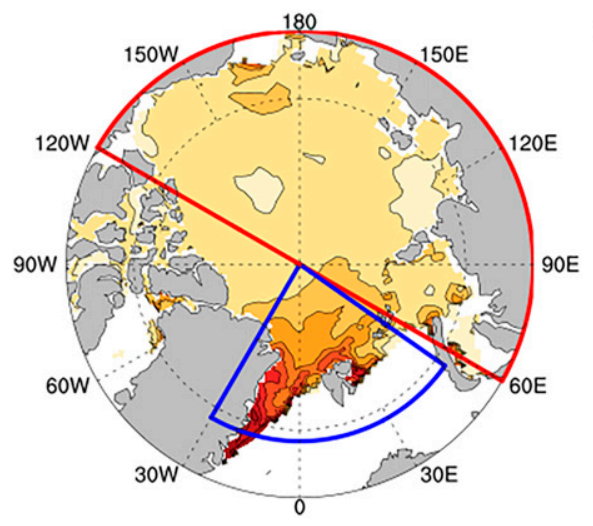

(cm)

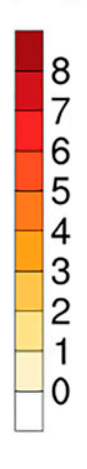

(cm)

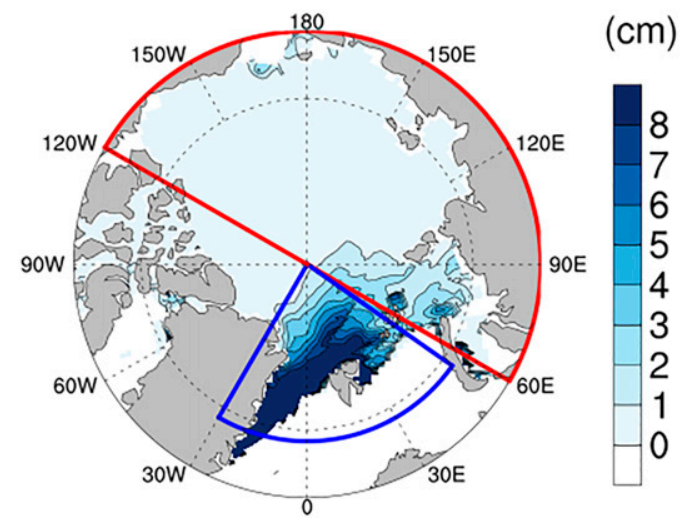

FIG. 3. Climatology and variability of snowfall and snow-ice formation. The wintertime (NDJFM) climatological mean accumulated (a) snowfall (SWE; $\mathrm{cm})$, (b) snow-ice formation $(\mathrm{cm})$, and one standard deviation of (c) snowfall $(\mathrm{SWE} ; \mathrm{cm})$ and $(\mathrm{d})$ snow-ice formation $(\mathrm{cm})$ on interannual time scales. The long-term trends of snowfall and snowice formation have been removed. Snowfall and snow-ice formation are from our CICE6-slab-ocean model with ERA5 historical forcing. The Eurasian-Pacific sector (Atlantic) of the Arctic denotes red (blue) lines in (c) and (d).

rate (Fig. 2d), corroborating our earlier finding of a link between snow depth and ice growth over the EurasianPacific sector of the Arctic. On subbasin scales, however, the spatial pattern of the reduced ice growth (Fig. 2d) does not visibly correspond to that of the snow depth (Fig. 2c). This may be due to other factors, such as atmospheric circulations, wind-driven ice drift, and initial (autumn-early winter) sea ice thickness, that modify the spatial patterns of both snow depth and ice thickness. To overcome this limitation, we designed idealized experiments that modulate snowfall in our sea ice model (see section 2). Unlike snow depth, which is a diagnostic variable of the sea ice model, snowfall is unambiguously a forcing for ice thickness and is an input variable for our sea ice model. Over the first-year sea ice region, which we define as locations where the October-average sea ice concentration is less than $15 \%$, the areally averaged interannual correlation between the winter (NDJFM) snowfall accumulation and the snow depth is about 0.80 (Fig. 4). This high correlation indicates that snowfall is a key factor controlling the snow depth variations, although there are various other factors affecting snow depth on regional scales, such as wind-blown snow (Pomeroy et al. 1997; Pomeroy and Li 2000), densification (Herron and Langway 1980), ridging (Roberts et al. 2019), and wind-driven sea ice flux convergence/divergence (Sturm and Stuefer 2013). 
(a) Snowfall \& snow depth

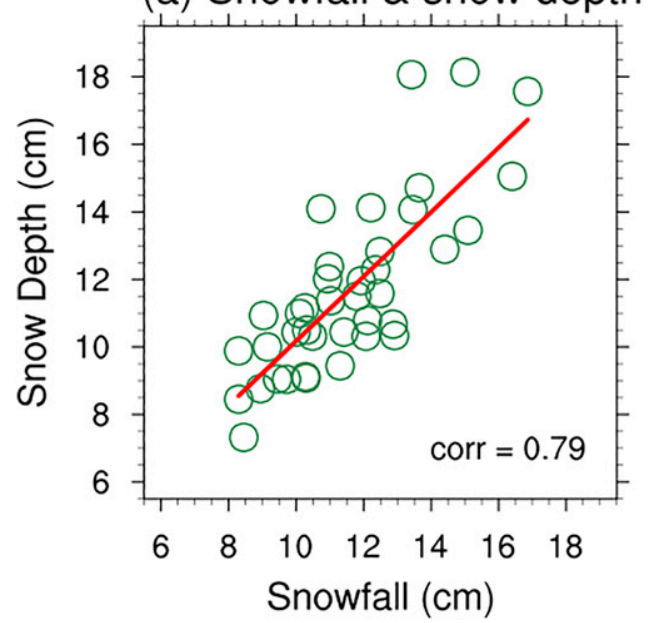

(b) Sea ice concentration (Oct)

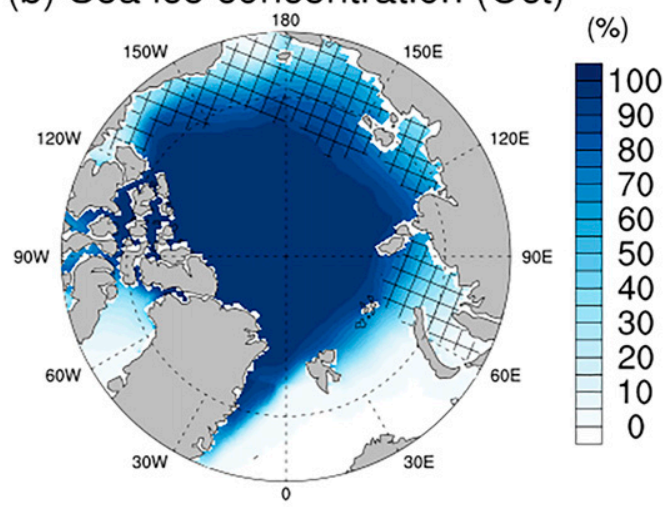

FIG. 4. Relationship between accumulated winter snowfall and snow depth over first-year sea ice. (a) The interannual relationship between wintertime (NDJFM) snowfall accumulation (abscissa; SWE; cm) and snow depth (ordinate; cm) from 1979/80 to 2017/18, averaged over the first-year sea ice of the Eurasian-Pacific sector of the Arctic. The red line is a linear regression line. (b) October sea ice concentration (shadings) averaged from 1979 to 2018 and the estimated first-year sea ice region (hatched). If the October sea ice concentration of a grid point is smaller than $15 \%$ in a specific year, the grid point is defined as a region of first-year sea ice, and the grids satisfying this condition for at least for one year are hatched in (b). Snowfall, snow depth, and sea ice concentration are from our CICE6-slab-ocean model with ERA5 historical forcing.

\section{c. The impact of winter snowfall on seasonal sea ice thickness}

To quantitatively assess the impact of anomalously large winter snowfall on sea ice, we performed idealized perturbation experiments using CICE6. Specifically, we imposed climatological-mean 6-hourly snowfall (the 5-month NDJFM climatological mean snowfall is shown in Fig. 3a) in the model from November to March for each of the 39 winters in the simulated period (see section 2). Because of the increasing trend of winter snowfall over the recent 40 years (Fig. 5a), we increased the snowfall climatology linearly from 1979/80 to 2017/18 following the linear regression line (red-dashed line in Fig. 5a for ERA5) for each month. It is unclear whether the increasing winter snowfall trends in these reanalysis products are reliable or not (Boisvert et al. 2018) because nonclimatic factors such as replacements of satellite sensors can affect the trend (Barrett et al. 2020). In these experiments, the same historical atmospheric boundary conditions are used to force the model. In summary, there are two experimental configurations: historical atmospheric boundary conditions (Hist ${ }_{i}$ ) and historical atmospheric boundary conditions with climatological snowfall from November to March $\left(\mathrm{cSnow}_{i}\right)$. These model simulations have been integrated through the winter and the following summer of each year and these two simulation outputs are subtracted $\left(\right.$ Hist $\left._{i}-\mathrm{cSnow}_{i}\right)$. The resulting differences quantify the impact of the winter snowfall anomalies on winter sea ice growth and the following season's snow-albedo feedbacks that eventually affect the seasonal sea ice thickness and summer sea ice extent.
In Figs. 5b-h, we plot 39-yr regression maps, showing the model-simulated seasonal snow depth (Figs. 5c-e) and sea ice thickness (Figs. 5f-h) responses to the winter snowfall anomalies (Fig. 5b) on interannual time scales. Here, the winter accumulated snowfall, the seasonal snow depth, and the seasonal ice thickness anomalies at each grid point are regressed on the winter accumulated snowfall anomaly averaged over the Eurasian-Pacific seas. Again, the long-term increasing trend of snowfall at each grid point was removed prior to calculating the winter accumulated snowfall anomaly averaged over the Eurasian-Pacific seas. The regression slopes are multiplied by one standard deviation of the snowfall anomaly averaged over the Eurasian-Pacific seas, which is approximately $1.0 \mathrm{~cm}$ (SWE) in ERA5. The resulting snowfall map exhibits positive anomalies over wide areas of the EurasianPacific seas, especially over the Chukchi Sea and the Kara Sea (Fig. 5b). A very similar pattern appears in other reanalysis datasets: JRA-55, MERRA-2, and CFSR (see supplemental Fig. 4). This geographic concentration may occur because a majority of Arctic snowfall is associated with cyclone activity (Webster et al. 2019) and many of these cyclones pass through the Chukchi Sea and the Barents-Kara Seas. The snowfall in MERRA-2 is about $20 \%-25 \%$ larger than in the other reanalysis products (Fig. 5a) and using MERRA-2 to force sea ice models is known to simulate thicker snow depth over sea ice (Blanchard-Wrigglesworth et al. 2018). Recent studies found that reanalysis products capture the satellite-observed and in situ-observed interannual variability in Arctic snowfall reasonably well (Barrett et al. 2020; Cabaj et al. 2020).

Because of the snowfall accumulation throughout the winter, the snow depth anomalies peak in late winter and spring, 
(a) Winter (NDJFM) Snowfall

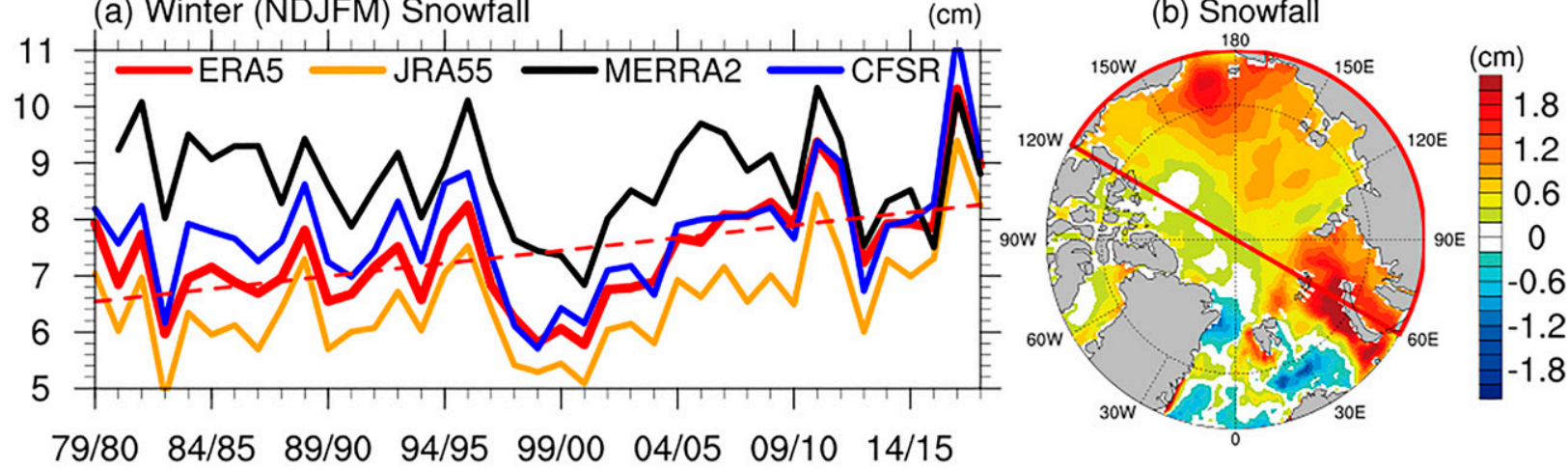

\section{Seasonal snow depth anomaly}

(c) DJF

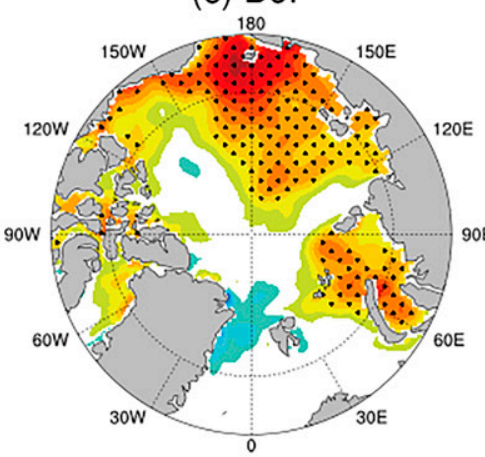

(d) MAM (e) JJA

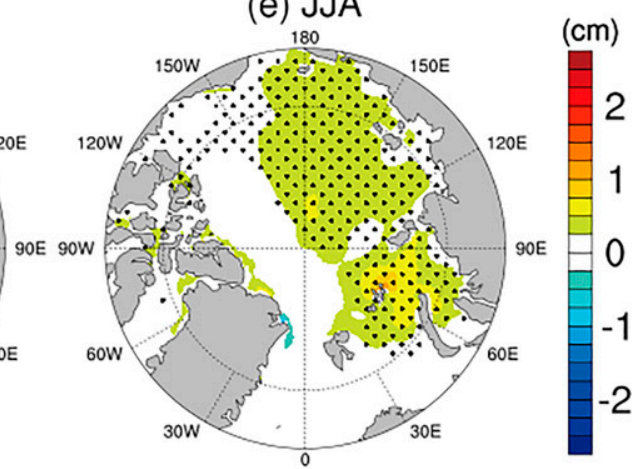

Seasonal ice thickness anomaly

(f) DJF 180

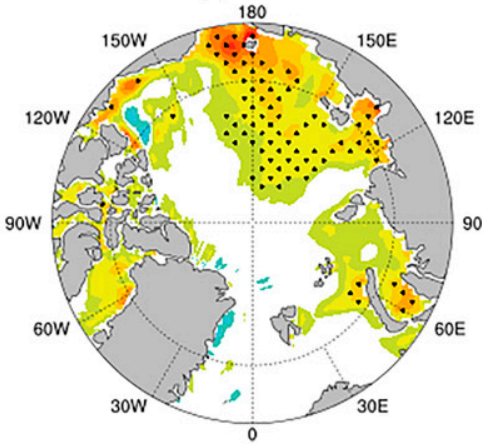

(g) MAM

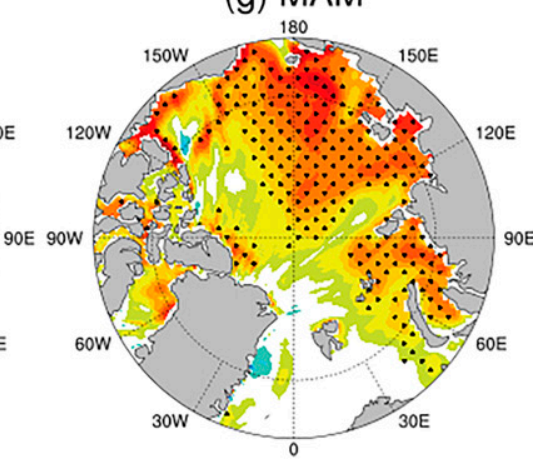

(h) JJA

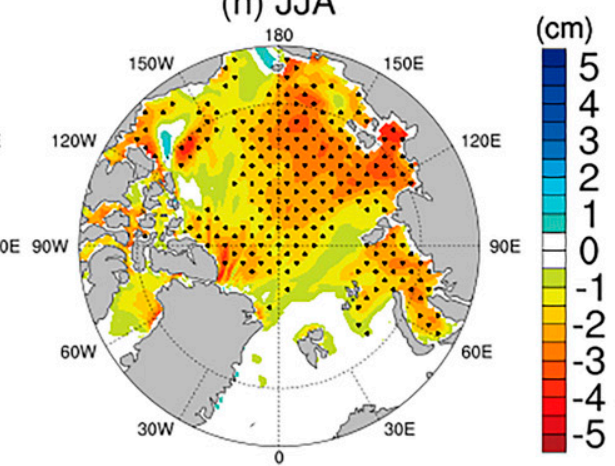

FIG. 5. The impact of winter snowfall on seasonal ice thickness. (a) The interannual variations of wintertime (NDJFM) accumulated snowfall (SWE; $\mathrm{cm}$ ) from ERA5, JRA-55, MERRA-2 and CFSR, averaged over the Eurasian-Pacific sector [red line in (b)]. The red dashed line in (a) is a linear regression line for the winter snowfall in ERA5. (b) The regression map of snowfall anomalies in winter per one standard deviation of winter snowfall anomaly averaged over the Eurasian-Pacific sector. Also shown are the seasonal (c)-(e) snow depth and (f)-(h) sea ice thickness responses in (c),(f) December-February, (d),(g) March-May, and (e),(h) June-August to the anomalously large winter snowfall. In $(\mathrm{c})-(\mathrm{h})$, statistically significant values $(p<0.05)$ are stippled. Snowfall, snow depth, and sea ice thickness are from our CICE6-slab-ocean model with ERA5 historical forcing.

from March to May (Fig. 5d). This regression map of ice thickness anomalies exhibits a basinwide ice thinning throughout the winter and spring in response to increased snow depth (Figs. $5 \mathrm{f}-\mathrm{h}$ ). The ice thickness anomaly is largest in the late winter and spring (Fig. 5g) and persists into the summer (Fig. 5h), although the increased snow depth in the spring (Fig. 5d) can increase surface albedo. From Fig. 5, we conclude that positive winter snowfall (SWE) anomalies, which typically deviate from the climatology by $1.0 \mathrm{~cm}$ (one standard deviation of the winter snowfall averaged over the Eurasian-Pacific 
(a) Winter (NDJFM) Snowfall

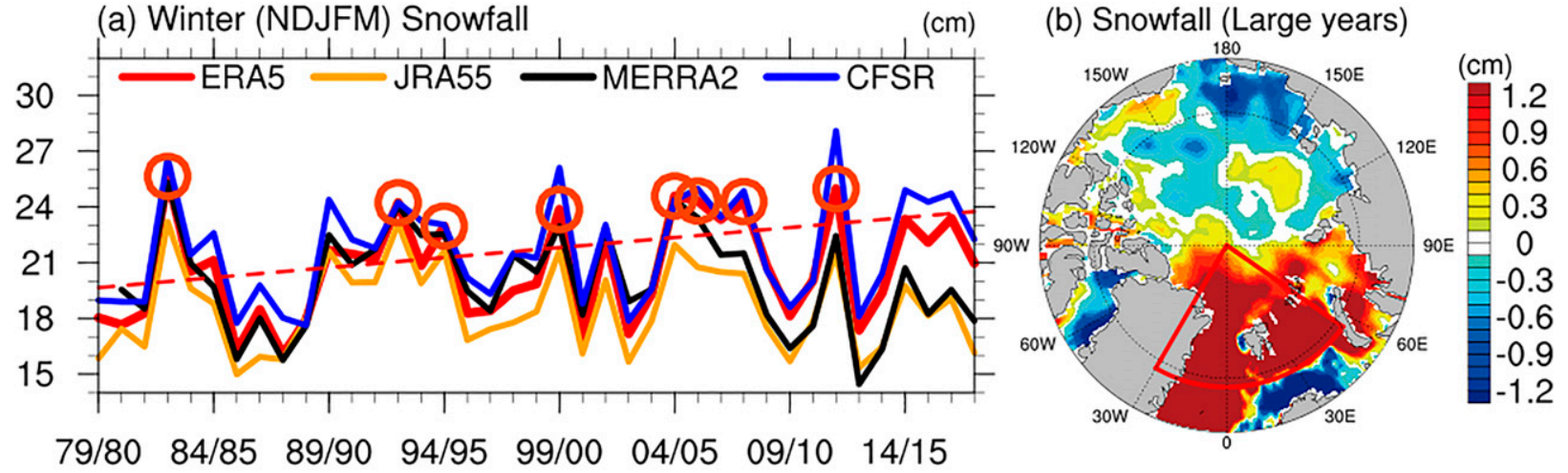

\section{Seasonal ice thickness anomaly}

(c) DJF

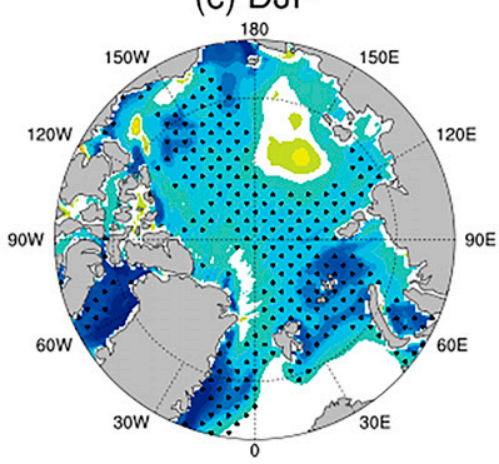

(d) MAM

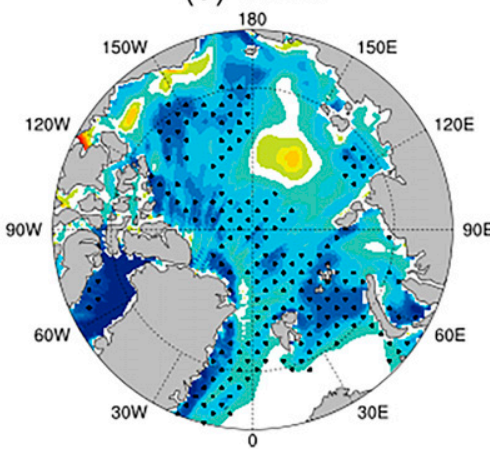

(e) JJA

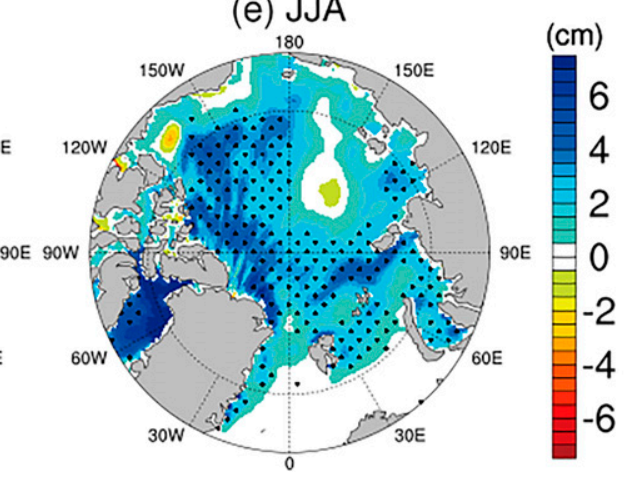

FIG. 6. The impact of the anomalously large winter snowfall over the Atlantic sector of the Arctic on seasonal ice thickness. (a) The interannual variations of wintertime (NDJFM) snowfall $(\mathrm{cm})$ from ERA5, JRA-55, MERRA-2, and CFSR, averaged over the Atlantic sector of the Arctic [red line in (b)]. The red dashed line in (a) is a linear regression line for the ERA5 winter snowfall. (b) Composite map of winter snowfall anomalies, and the composite maps of seasonal ice thickness responses in (c) December-February, (d) March-May, and (e) June-August to anomalously large winter snowfall (above one standard deviation anomaly) over the Atlantic sector during the winters of 1982/83, 1992/93, 1994/95, 1999/00, 2004/05, 2005/06, 2007/08, and 2011/12 [red circles in (a)]. Snowfall and sea ice thickness are from our CICE6-slab-ocean model with ERA5 historical forcing.

seas), suppress the winter ice growth and can cause basinwide ice thinning through the following spring and summer.

On the contrary, idealized experiments also indicate that anomalously large winter snowfall over the Atlantic seas, defined as larger than one standard deviation on interannual time scales, rather causes ice thickening (Fig. 6). Here, the sea ice thickening to the anomalously large snowfall appears only in the extreme snowfall years. The simple linear regression between the winter snowfall anomalies over the Atlantic sector of the Arctic and the seasonal sea ice thickness does not produce any statistically significant sea ice thickness responses, probably because of the compensation between the snow insulation effect and the snow-ice formation. As shown in previous studies (Granskog et al. 2017; Merkouriadi et al. 2017, 2020), extreme snowfall events over the Atlantic sector of the Arctic substantially increase snow and ice formation and thereby can increase ice thickness.

Because the anomalously large snowfall over the Atlantic sector of the Arctic is often accompanied by anomalously less snowfall over the Pacific sector of the Arctic (Fig. 6b), reduced snowfall over the Eurasian-Pacific sector causes sea ice thickening in winter and spring (Figs. 6c,d) that can persist into the summer (Fig. 6e). Figures 5 and 6 indicate that small changes in winter snowfall pattern can cause basinwide sea ice thickness changes. However, this ice thickness pattern associated with snowfall anomalies may be difficult to discern in observations because these snowfall anomalies are accompanied by atmospheric circulation changes (Cohen et al. 2017), which can also change sea ice thickness via wind-driven ice flux divergence (Jakobson et al. 2019).

\section{d. Covariance between winter snowfall and downward longwave radiation}

Because precipitation is dynamically tied to clouds and water vapor, anomalously large wintertime snowfall is accompanied by stronger downward longwave radiation. On interannual time scales, the winter snowfall is strongly correlated with downward longwave radiation over the Eurasian-Pacific seas, and both exhibit increasing trends since early 2000s (Fig. 7a). In addition, downward longwave radiation is closely coupled to surface air temperature during the winter (Woods et al. 2013; Park et al. 2015) and is often accompanied by 
(a) Snowfall \& Longwave (NDJFM)

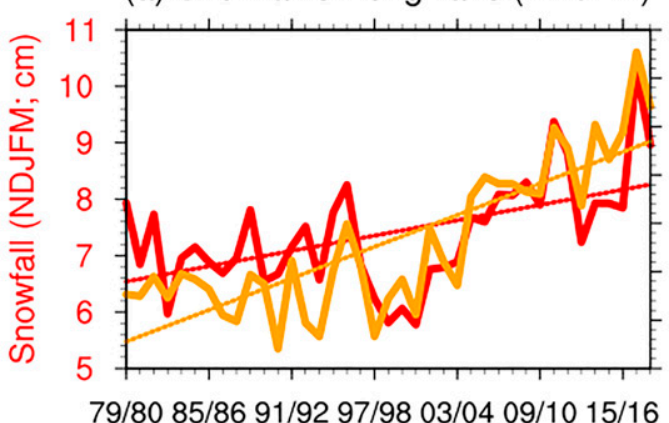

(b) T2m \& Specific humidity (NDJFM)

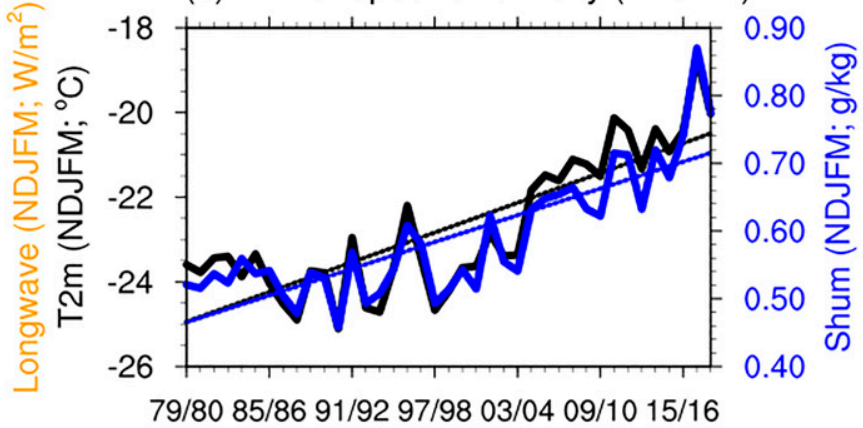

(c) Snowfall

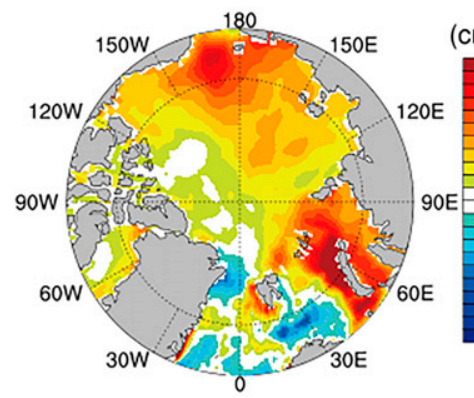

(f) Downward longwave

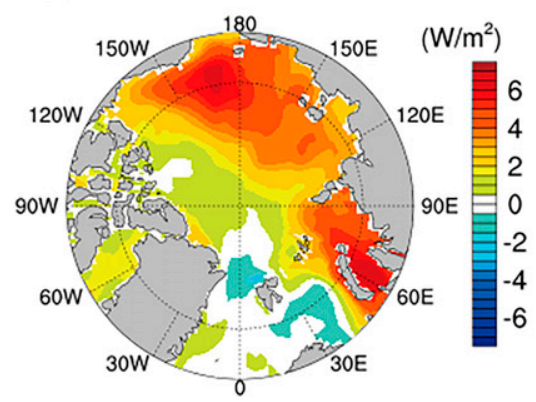

(d) $2 \mathrm{~m}$ temperature

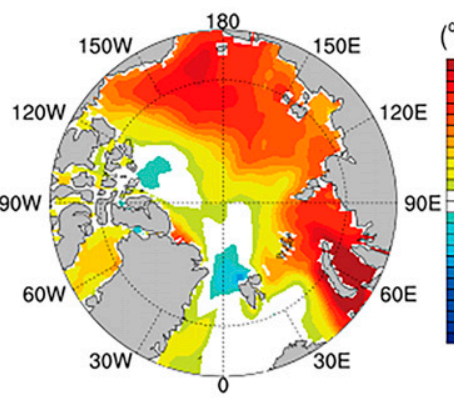

(g) Cloud liquid water

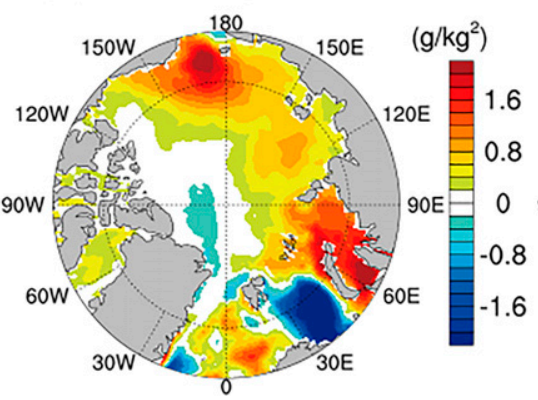

(e) Specific humidity

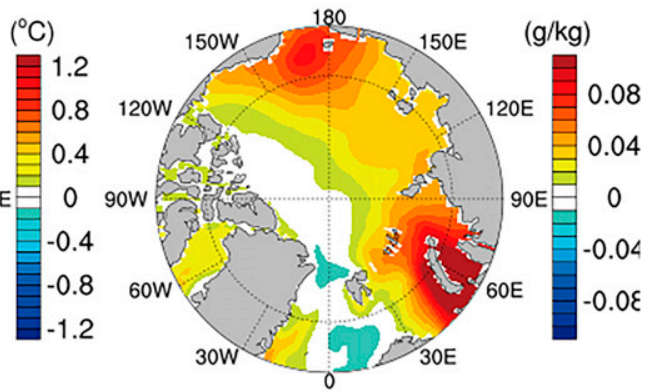

(h) Sea level pressure

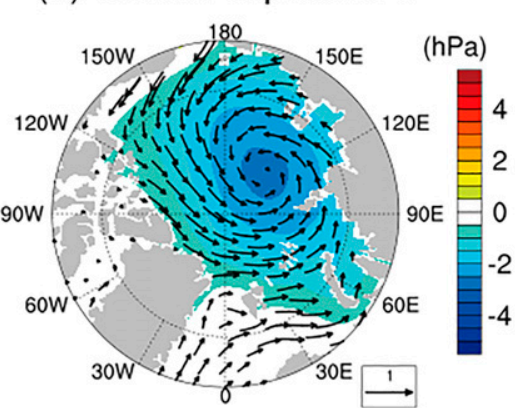

FIG. 7. Covariance between winter clouds, snowfall, and downward longwave radiation. The interannual variations of ERA5's wintertime (NDJFM) (a) snowfall (SWE; red) and downward longwave radiation (orange) and (b) surface air temperature (black) and surface specific humidity (blue) averaged over the Eurasian-Pacific sector of the Arctic. The dotted lines are linear regression lines. Also shown are regression maps of (c) snowfall (SWE), (d) 2-m air temperature, (e) near-surface specific humidity, (f) downward longwave radiation, (g) cloud liquid water, and (h) sea level pressure (shadings) with winds (vectors) per one standard deviation of snowfall anomaly. The regression map of snowfall in (c) is identical to Fig. 5 b.

surface air moistening. The interannual variabilities of $2-\mathrm{m}$ air temperature and near-surface specific humidity, averaged over the Eurasian-Pacific seas, are very similar to each other (Fig. 7b) and are strongly correlated with those of snowfall/ downward longwave radiation (cf. Figs. 7a,b). The correlation coefficient between snowfall and downward longwave radiation (2-m air temperature and near-surface specific humidity), averaged over the Eurasian-Pacific seas, is 0.66 (0.64 and $0.64)$ and these values are statistically significant $(p<0.05)$. The spatial patterns of snowfall (Fig. 7c), downward longwave radiation (Fig. 7f), 2-m air temperature, and near-surface specific humidity (Figs. 7d,e) anomalies are also similar to one another. The spatial pattern of cloud liquid water anomaly (Fig. $7 \mathrm{~g}$ ) is also very similar to those of snowfall and downward longwave radiation.

The surface air warming is often associated with the development of low pressure with cyclonic circulation (Fig. 7h) via hydrostatic balance (Kim et al. 2019). Because the wintertime cyclonic sea ice drift can decrease sea ice thickness over the Eurasian seas (Williams et al. 2016; Park and Stewart 2018), the snowfall-induced negative sea ice thickness anomalies (Fig. 5f) are likely to further decrease. These air temperature and humidity anomalies are in fact directly linked to the poleward moisture flux anomalies: the development of southwesterlies 

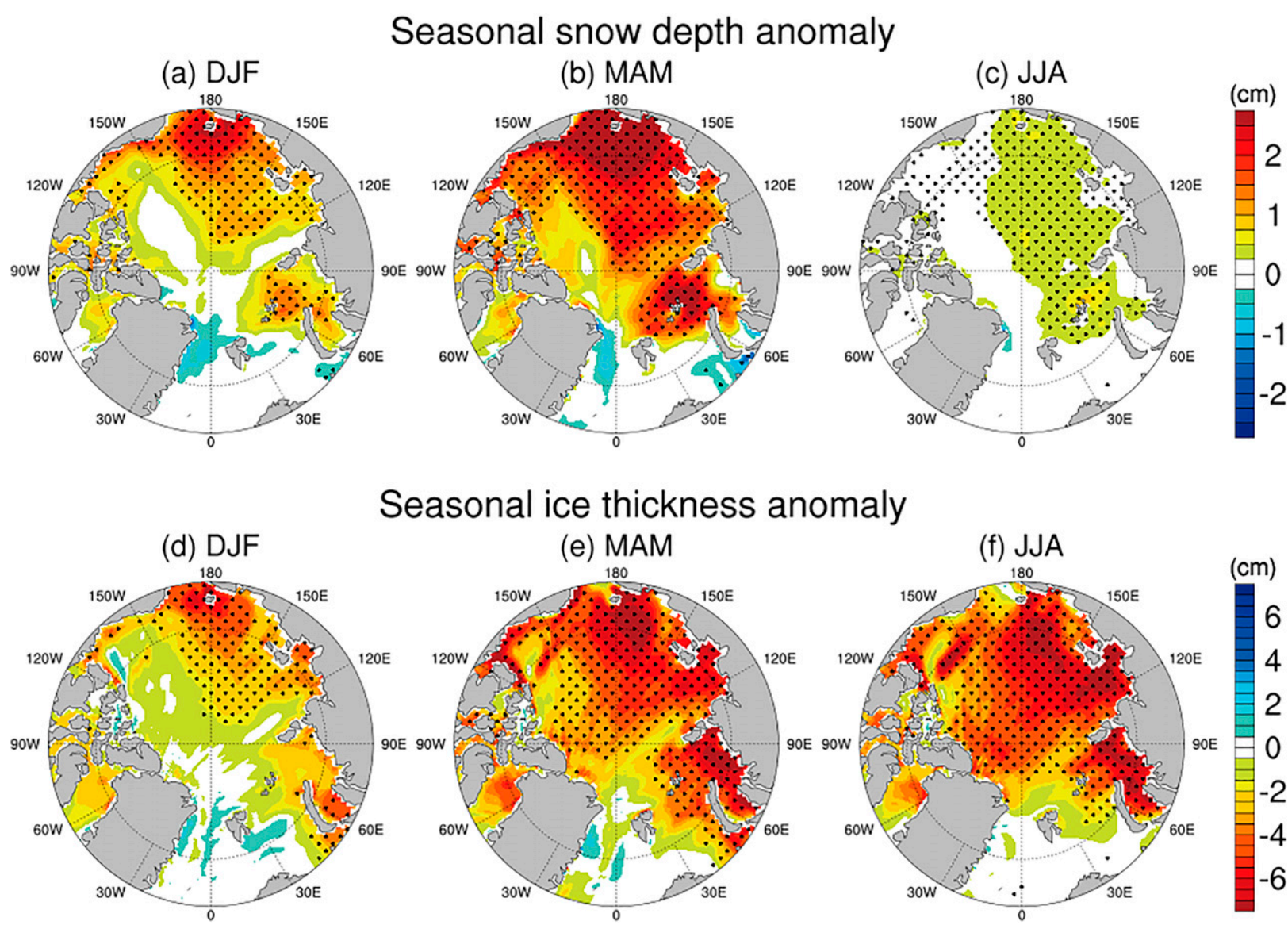

FIG. 8. The net effect of the winter snowfall and accompanying atmospheric forcings on sea ice thickness. The seasonal (a)-(c) snow depth and (d)-(f) sea ice thickness responses in (a),(d) DJF, (b),(e) MAM, and (c),(f) JJA to the anomalously large winter snowfall combined with strong downward longwave radiation, which is also accompanied by the surface air warming and moistening. Statistically significant values $(p<0.05)$ are stippled. Snow depth and sea ice thickness are from our CICE6-slab-ocean model with ERA5 historical forcing.

over the Barents-Kara Seas and the Chukchi Sea (vectors in Fig. 7h) contributes to the increased poleward moisture flux that strengthens downward longwave radiation (Park et al. 2015; Hegyi and Taylor 2018), and likely increases precipitation (snowfall) over the Eurasian-Pacific seas as well.

\section{e. The net effect of increased snowfall and the accompanying atmospheric forcings}

To quantitatively assess the combined impact of snowfall, longwave radiation, air temperature, and humidity anomalies on sea ice, we performed additional idealized perturbation experiments for all of the 39 winters in our sea ice model simulation. Similar to the cSnow experiments described above, we created a model configuration in which the NDJFM downward longwave radiation, surface air temperature, specific humidity, and snowfall are replaced by their respective climatological means. We refer to this idealized experiment as "cSnow + cDLW + cT + cq" (see section 2). The combined impact of the increased snowfall, stronger downward longwave radiation, and the associated surface air warming/moistening can be estimated from the difference between the historical simulation and the idealized experiment, that is, Hist $-(\mathrm{cSnow}+\mathrm{cDLW}+\mathrm{cT}+\mathrm{cq})$. Here the climatological mean values of downward longwave radiation, surface air temperature, and specific humidity are defined via linear regression lines, shown in Figs. 7a and 7b.

The responses of seasonal snow depth anomalies (Figs. 8a-c) to the combined forcings are qualitatively similar to those of the snowfall forcing alone (Figs. 5c-e), which we attribute to the surface air moistening keeping the surface relative humidity and the associated snow sublimation almost unchanged. With the snow depth approximately unchanged, the increased downward longwave radiation and surface air warming serve to further decrease the ice thickness. Consequently, the sea ice thickness anomalies show a larger thinning in these experiments (Fig. 8d) than in response to snowfall forcing alone (Fig. 5f) in DecemberFebruary (DJF). The suppression of winter ice growth is followed by the ice thinning in the ensuing spring and summer. In March-May (MAM), sea ice thickness decreases by around 4-8 cm (Fig. 8e), doubling the ice thickness anomalies driven by the snowfall anomalies alone (cf. Figs. $8 \mathrm{e}$ and $5 \mathrm{~g}$ ). The spatial patterns of the ice thickness anomalies exhibit a pronounced ice thinning throughout the season, not only over the Eurasian-Pacific 


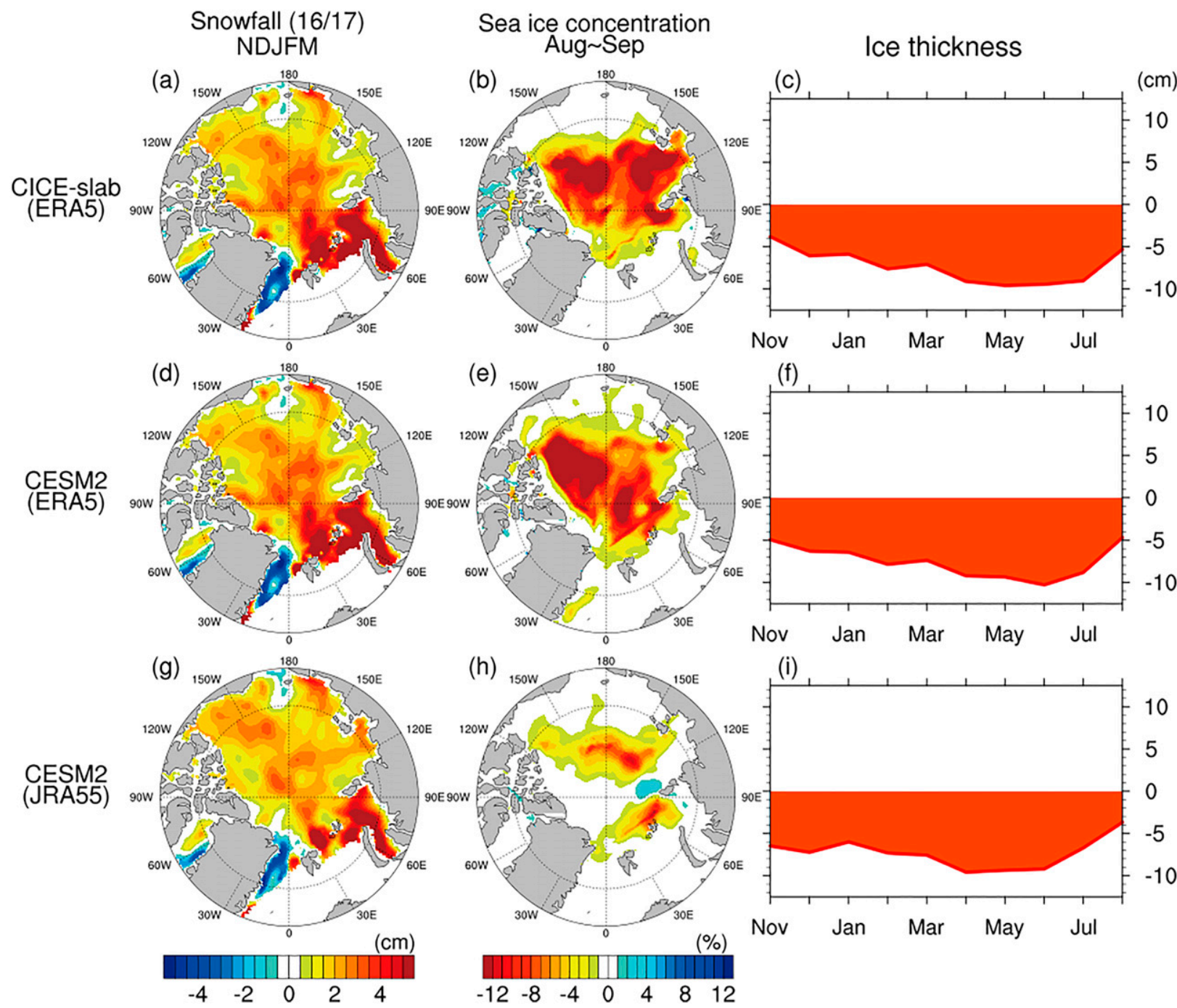

FIG. 9. The 2016/17 sea ice responses simulated by our CICE6-slab-ocean model and CESM2-full-ocean models. (a),(d),(g) Accumulated snowfall anomalies (SWE; cm) during the winters of 2016/17 from ERA5 and JRA-55. Simulated responses of (b),(e),(h) summer (August-September) sea ice concentration and (c),(f),(i) seasonal sea ice thickness to the combined effect of preceding winter snowfall and downward longwave radiation, which is also accompanied by the surface air warming and moistening. Results in (a) and (d) are from ERA5 and in (g) from JRA-55. Results in (b) and (c) are derived from our CICE6-slab-ocean model with ERA5 forcing, in (e) and (f) are derived from our CESM2-full-ocean model with ERA5 forcing, and in (h) and (i) are derived from our CESM2-full-ocean model with JRA-55 forcing. Note that (a) and (d) are identical.

seas, but also over the entire Arctic (Figs. 8d-f), and the majority these ice thickness anomalies are statistically significant, exceeding $95 \%$ confidence interval derived from the interannual ice thickness variations (stippling in Fig. 8).

Because the basinwide ice thinning persists into the summer (Fig. 8f), the summer sea ice extent is likely to be affected. Indeed, our model simulates a nonnegligible dependence of the summer sea ice extent on the preceding winter's snowfall and downward longwave radiation anomalies. Several years exhibited a notable reduction of the summer sea ice extent, particularly in recent years, during which the multidecadal trend toward thinner sea ice might have increased the sensitivity of ice thickness to winter clouds and snowfall. In the winter of 2016/17, warm and moist air transported from lower latitudes by atmospheric rivers caused an unprecedentedly warm Arctic, suppressing sea ice growth (Hegyi and Taylor 2018). The wintertime snowfall was also large in the winter of 2016/17 not only over the Eurasian-Pacific seas but also over the wide areas of the Arctic, including the Barents and Kara Seas (Figs. 9a,g). CICE6 simulations show that the large snowfall combined with positive downward longwave and air temperature anomalies in the winter of 2016/17 suppressed the winter sea ice growth and decreased the spring and early summer sea ice thickness by $\sim 10 \mathrm{~cm}$ over the Eurasian-Pacific seas (Fig. 9c). This seasonally persistent ice thinning was followed by a notable reduction of ice cover in 


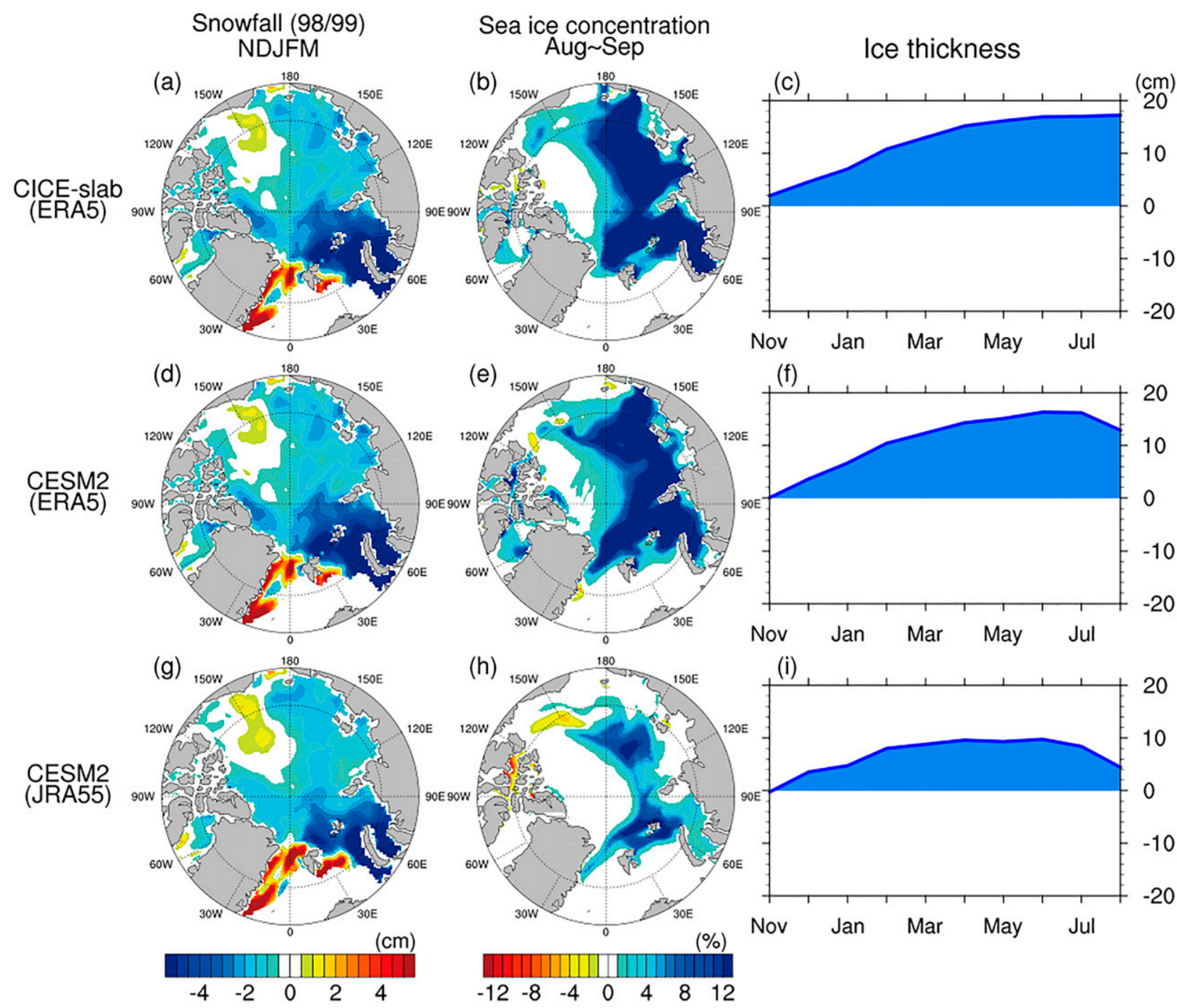

FIG. 10. The 1998/99 sea ice responses simulated by our CICE6-slab-ocean model and CESM2-full-ocean models. (a),(d),(g) Accumulated snowfall anomalies (SWE; cm) during the winter of 1998/99 from ERA5 and JRA-55. Simulated responses of (b),(e),(h) summer (August-September) sea ice concentration and (c),(f),(i) seasonal sea ice thickness to the combined effect of preceding winter snowfall and downward longwave radiation, which is also accompanied by the surface air warming and moistening. Results in (a) and (d) are from ERA5 and in (g) from JRA-55. Results in (b) and (c) are derived from our CICE6-slab-ocean model with ERA5 forcing, in (e) and (f) are derived from our CESM2-full-ocean model with ERA5 forcing, and in (h) and (i) are derived from our CESM2-full-ocean model with JRA-55 forcing. Note that (a) and (d) are identical.

August-September (Fig. 9b), corresponding to an approximately $30 \%$ reduction in sea ice extent.

Similarly, our CICE6 simulations also indicate that anomalously small snowfall during the winter of 1998/99 (Figs. $10 \mathrm{a}, \mathrm{g})$ accelerated the winter sea ice growth and increased the spring and summer sea ice thickness up to $17 \mathrm{~cm}$ (Fig. 10c). This was followed by a large increase in summer sea ice concentration-more than $15 \%$ over wide areas of the Arctic Ocean in August-September (Fig. 10b). These results are consistent with previous studies (Liu and Key 2014; Park et al. 2015; Letterly et al. 2016) finding that downward longwave radiation anomalies in the Eurasian-Pacific seas precondition sea ice thickness, which in turn has nontrivial influence on summer sea ice extent. This study further presents that the accompanying increase in snowfall can double the ice thinning and thereby suggests that winter snowfall should be factored into quantifying the seasonal sea ice thickness and extent, although summer weather often exerts a strong influence on September sea ice extent.

\section{f. Sea ice model coupled to a full-ocean model}

A caveat of our CICE6-slab-ocean model is that the ocean mixed layer depth cannot respond to changes in snowfall and 
downward longwave radiation. Such changes in the ocean mixed layer could feed back on sea ice growth, and so excluding them in CICE6 might bias our results. To test the robustness of our CICE6-slab-ocean model simulations, we utilized the CESM2 (Danabasoglu et al. 2020) forced by both ERA5 and JRA-55 atmospheric boundary conditions (see section 2).

The interannual variability of winter snowfall over the Eurasian-Pacific seas in JRA-55 is very similar to that of ERA5 (Fig. 5a), except that the wintertime mean snowfall is about $10 \%$ smaller than that of ERA5. While using a fullocean model has merit in realistically simulating the interaction between sea ice growth/melting and the ocean mixed layer, it is difficult to control the SSTs over the marginal seas of the Arctic, which strongly influence sea ice extent (Bitz et al. 2005). Consequently, CESM2 forced by JRA-55 and ERA5 atmospheric boundary conditions underestimates the summer sea ice extent (Fig. 1a), although the observed variability and trend of summer sea ice extent are reasonably well simulated by CESM2 (magenta and sky-blue lines of Fig. 1a). While the CESM2-simulated interannual variations of snow depth averaged over the entire Arctic are similar to those of PIOMAS and NESOSIM, the wintertime snow depth is about $30 \%$ smaller than those of PIOMAS and NESOSIM (Fig. 1b).

Using CESM2 with JRA-55 atmospheric boundary conditions, we performed the same perturbation experiments for the two extreme cases: the winters of 1998/99 and 2016/17. Consistent with the CICE6-slab-ocean model simulations, CESM2 simulations show that the anomalously large snowfall (Figs. 9d,g), combined with other thermodynamic forcings, during the winter of 2016/17 suppressed the winter sea ice growth and decreased the spring and early summer sea ice thickness by $\sim 10 \mathrm{~cm}$ (Figs. 9f,i). These sea ice thickness anomalies are similar to those simulated in our CICE6-slab-ocean model (cf. Figs. 9c and 9f). This seasonally persistent ice thinning is followed by a reduction of ice cover in August and September in CESM2 simulations forced by ERA5 (Fig. 9e) and JRA-55 (Fig. 9h). Note that the response of summer sea ice cover is much larger when ERA5 data are used to drive the CESM2 ocean-sea ice model. We caution that direct comparisons of summer sea ice concentration anomalies between the CICE6-slab-ocean model and the CESM2-full-ocean model outputs should be interpreted carefully because CESM2-full-ocean model simulates a $\sim 10 \%$ smaller summer sea ice extent than is simulated by the CICE6-slab-ocean model (Fig. 1a).

Consistent with our CICE6-slab-ocean model simulations, the anomalously small snowfall (Figs. 10d,g) and the accompanying forcings (weak downward longwave radiation, surface cooling and drying) during the winter of 1998/ 99 substantially increased sea ice thickness throughout the seasons (Figs. 10f,i). The sea ice thickening was followed by an increase in sea ice concentration in the summer of 1999 over wide areas of the Arctic Ocean (Fig. 10e). It can be concluded that the simulation results from the CESM2-fullocean model, both with ERA5 and JRA-55 atmospheric boundary conditions, generally corroborate those of the CICE6 slab-ocean model with ERA5 atmospheric boundary conditions.

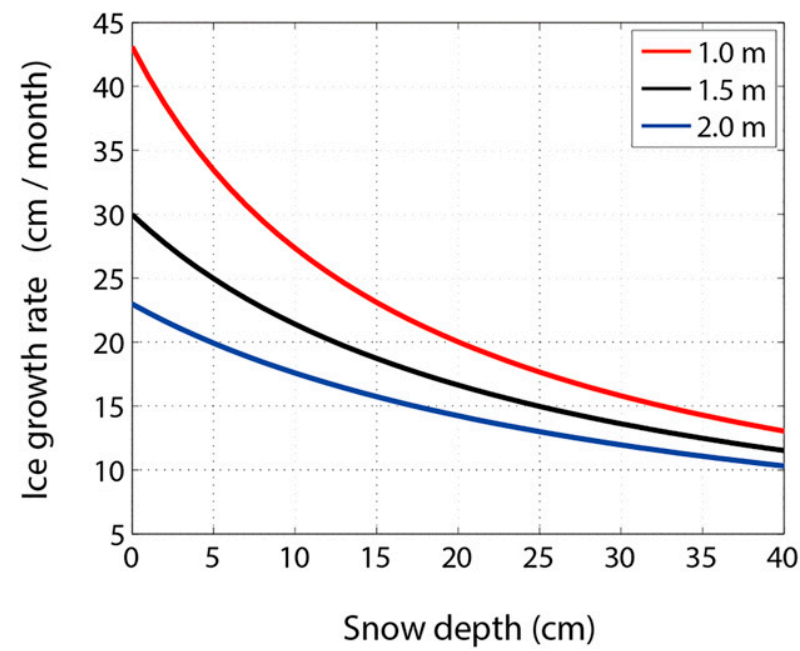

FIG. 11. Sensitivity of ice growth rate to snow depth estimated by a simple 1D model. Sensitivity of wintertime ice growth rate (ordinate; $\mathrm{cm} \mathrm{month}^{-1}$ ) to snow depth (abscissa; $\mathrm{cm}$ ) and ice thickness (red, black, and blue lines), simulated by a simple 1D sea ice model. The red, black, and blue lines correspond to sea ice thickness $h_{i}=1.0,1.5$, and $2.0 \mathrm{~m}$ respectively.

\section{Summary and discussion}

In summary, our model simulations demonstrate that small changes in winter snowfall over the Eurasian-Pacific seas can strongly impact not only the winter sea ice growth, but also the extent and thickness of sea ice in the following seasons. A key finding of this study is that a small increase in winter snowfall accompanied by an increase in downward longwave radiation and surface warming/moistening drives anomalous sea ice thinning that persists into summer. Although the increased spring snow depth might increase surface albedo (which was not investigated in this study), the effect of sea ice thinning on summer sea ice is likely to be larger than the spring snow-albedo effect. In extreme cases, the basinwide ice thinning is followed by a shrinking of summer ice extent. This indicates that winter snowfall anomalies, along with accompanying anomalies in downward longwave radiation and surface air warming/moistening over the Eurasian-Pacific seas, may serve as a useful predictor of the following summer sea ice extent. However, our study also highlights the sensitivity of Arctic sea ice growth to snowfall pattern: increased snowfall over the Atlantic sector accompanied by decreased snowfall over the Pacific sector (Fig. 6b) can cause basinwide sea ice thickening (Figs. 6c,d).

The results from the idealized $1 \mathrm{D}$ model demonstrate that snow has an increasing influence on winter sea ice growth as sea ice becomes thinner (Fig. 11). This influence may be compounded by the tendency of a warmer Arctic to be accompanied by increasing snowfall from late autumn to early spring in future decades (Webster et al. 2021). However, while Arctic sea ice is projected to become thinner with future climate change, snow depth is also projected to decline (Hezel et al. 2012; Webster et al. 2018, 2021). The projected decrease 
in snow accumulation is attributed to enhanced surface melt in summer and later freeze-up of sea ice in autumn (Hezel et al. 2012; Webster et al. 2021). In late spring, projected decreases in spring/summer snowfall (a majority of springsummer snowfall becomes rainfall) (Vihma et al. 2016) may lead to a further reduction in snow accumulation. As noted in a recent study (Petty et al. 2018a), the Arctic may be transitioning to a state where the sea ice growth is more controlled by the autumn-winter atmosphere-ocean forcing variations than the autumn sea ice thickness. Our findings suggest that small changes in the pattern of winter snowfall and the accompanying atmospheric forcings may become increasingly influential on the seasonal sea ice growth and thickness in the coming decades (e.g., Maykut 1978).

Acknowledgments. This work is supported by the National Research Foundation of Korea (NRF; 2020R1A2C2010025) and the U.S. National Science Foundation under Grant OCE-1751386. We thank three anonymous reviewers for their helpful and constructive comments, which helped us to improve the manuscript. We also acknowledge computational support from the KMA Supercomputing Center.

Data availability statement. Data used in this study are publicly available. ERA5 data can be downloaded from the Copernicus repository https://cds.climate.copernicus.eu/ cdsapp\#!/dataset/reanalysis-era5-single-levels-monthly-means. JRA-55 data are available at https://rda.ucar.edu/datasets/ ds628.1/. MERRA-2 data are available at https://disc.gsfc. nasa.gov/datasets? page $=1 \&$ source $=$ Models $\% 2$ FAnalyses $\% 20$ MERRA-2\&temporalResolution $=1 \% 20$ month $/$. CFSR data are available at https://rda.ucar.edu/datasets/ds093.2/ and https://rda.ucar.edu/datasets/ds094.2/. PIOMAS and NESOSIM products can be obtained from http://psc.apl.uw.edu/ research/projects/arctic-sea-ice-volume-anomaly/data/model_ grid and https://earth.gsfc.nasa.gov/cryo/data/nasa-euleriansnow-sea-ice-model-nesosim, respectively. The satelliteobserved sea ice extent version 3 is available from the NSIDC at https://nsidc.org/data/g02135. Monthly climate model outputs for CESM2 simulations conducted for the purpose of this study are available on CRAY XC40 server at the National Center for Meteorological Supercomputer. These data can be downloaded from GitHub: https:/github.com/wilim7942/ model_results-winter_snowfall.

\section{APPENDIX}

\section{Given Parameters}

The parameters that we used for the Eurasian-Pacific sector of the Arctic Ocean are as follows:

$c_{p}$ : specific heat capacity of air $\left(1005 \mathrm{~J} \mathrm{~kg}^{-1} \mathrm{~K}^{-1}\right)$

$C_{D}$ : turbulent transfer coefficient over sea ice (0.0013)

$k_{i}$ : thermal conductivity of ice $\left(2.04 \mathrm{~W} \mathrm{~m}^{-1} \mathrm{~K}^{-1}\right)$

$k_{s}$ : thermal conductivity of snow $\left(0.31 \mathrm{~W} \mathrm{~m}^{-1} \mathrm{~K}^{-1}\right)$

$L_{f}$ : latent heat of fusion at $0 \mathrm{~K}\left(3.340 \times 10^{5} \mathrm{~J} \mathrm{~kg}^{-1}\right)$

$T_{f}$ : freezing temperature of seawater $(271.3 \mathrm{~K})$

$\rho_{I}$ :density of ice $\left(930 \mathrm{~kg} \mathrm{~m}^{-3}\right)$ $\rho_{a}$ : density of air, $\left(1.275 \mathrm{~kg} \mathrm{~m}^{-3}\right)$

$\sigma$ : Stefan-Boltzmann constant $\left(5.67 \times 10^{-8} \mathrm{~W} \mathrm{~m}^{-2} \mathrm{~K}^{-4}\right)$

$\mathbf{U}$ : wind speed at $10 \mathrm{~m}\left(2.56 \mathrm{~m} \mathrm{~s}^{-1}\right)$

$h_{i}$ : sea ice thickness $(1.38 \mathrm{~m})$

$T_{a}: 2-\mathrm{m}$ air temperature $(249.85 \mathrm{~K})$

$q_{a}: 2-\mathrm{m}$ specific humidity $\left(0.57 \mathrm{~g} \mathrm{~kg}^{-1}\right)$

$F_{\mathrm{LW}}^{\downarrow}$ : downward longwave radiation at the surface (182.1

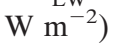

Because of its simplicity, the simple 1D model yields further physical insight into the effect of snow depth on ice growth. The intuition is that thicker snow produces lower snow surface temperature by decreasing the average conductivity of the snow/ice layer, which subsequently decrease upward longwave radiation $\left(F_{\mathrm{LW}}^{\uparrow}\right)$ and sensible heat flux $\left(\mathrm{SHF}^{\uparrow}\right)$.

\section{REFERENCES}

Barrett, A. P., J. C. Stroeve, and M. C. Serreze, 2020: Arctic Ocean precipitation from atmospheric reanalyses and comparisons with North Pole drifting station records. J. Geophys. Res. Oceans, 125, e2019JC015415, https://doi.org/10.1029/ 2019JC015415.

Bintanja, R., and O. Andry, 2017: Towards a rain-dominated Arctic. Nat. Climate Change, 7, 263-267, https://doi.org/10. 1038/nclimate3240.

Bitz, C. M., M. M. Holland, E. C. Hunke, and R. E. Moritz, 2005: Maintenance of the sea-ice edge. J. Climate, 18, 2903-2921, https://doi.org/10.1175/JCLI3428.1.

Blanchard-Wrigglesworth, E., M. A. Webster, S. L. Farrell, and C. M. Bitz, 2018: Reconstruction of snow on Arctic sea ice. $J$. Geophys. Res. Oceans, 123, 3588-3602, https://doi.org/10. 1002/2017JC013364.

Boisvert, L. N., M. A. Webster, A. A. Petty, T. Markus, D. H. Bromwich, and R. I. Cullather, 2018: Intercomparison of precipitation estimates over the Arctic Ocean and its peripheral seas from reanalyses. J. Climate, 31, 8441-8462, https://doi. org/10.1175/JCLI-D-18-0125.1.

Briegleb, B. P., and B. Light, 2007: A delta-Eddington multiple scattering parameterization for solar radiation in the sea ice component of the community climate system model. NCAR Tech. Note NCAR/TN-472+STR, 100 pp.

Bromwich, D. H., A. B. Wilson, L.-S. Bai, G. W. K. Moore, and P. Bauer, 2016: A comparison of the regional Arctic system reanalysis and the global ERA-Interim reanalysis for the Arctic. Quart. J. Roy. Meteor. Soc., 142, 644-658, https://doi. org/10.1002/qj.2527.

Cabaj, A., P. J. Kushner, C. G. Fletcher, S. Howell, and A. A. Petty, 2020: Constraining reanalysis snowfall over the Arctic Ocean using CloudSat observations. Geophys. Res. Lett., 47, e2019GL086426, https://doi.org/10.1029/2019GL086426.

Cohen, L., S. R. Hudson, V. P. Walden, R. M. Graham, and M. A. Granskog, 2017: Meteorological conditions in a thinner Arctic sea ice regime from winter to summer during the Norwegian Young Sea Ice expedition (N-ICE2015). J. Geophys. Res. Atmos., 122, 7235-7259, https://doi.org/10.1002/2016JD026034.

Cole, S. T., M. L. Timmermans, J. M. Toole, R. A. Krishfield, and F. T. Thwaites, 2014: Ekman veering, internal waves, and turbulence observed under Arctic sea ice. J. Phys. Oceanogr., 44, 1306-1328, https://doi.org/10.1175/JPO-D-12-0191.1. 
Collow, T. W., W. Wang, A. Kumar, and J. Zhang, 2015: Improving Arctic sea ice prediction using PIOMAS initial sea ice thickness in a coupled ocean-atmosphere model. Mon. Wea. Rev., 143, 4618-4630, https://doi.org/10.1175/MWR-D-15-0097.1.

Craig, T., and Coauthors, 2018: CICE-Consortium/CICE: CICE version 6.0.0, https://doi.org/10.5281/zenodo.1900639.

Danabasoglu, G., and Coauthors, 2020: The Community Earth System Model version 2 (CESM2). J. Adv. Model. Earth Syst., 12, e2019MS001916, https://doi.org/10.1029/2019MS001916.

Dee, D. P., and Coauthors, 2011: The ERA-Interim reanalysis: Configuration and performance of the data assimilation system. Quart. J. Roy. Meteor. Soc., 137, 553-597, https://doi.org/ 10.1002/qj.828.

Feltham, D. L., N. Untersteiner, J. S. Wettlaufer, and M. G. Worster, 2006: Sea ice is a mushy layer. Geophys. Res. Lett., 33, L14501, https://doi.org/10.1029/2006GL026290.

Fetterer, F., K. Knowles, W. N. Meier, M. Savoie, and A. K. Windnagel, 2017: Sea ice index, version 3. National Snow and Ice Data Center, accessed 15 March 2020, https://doi.org/10. 7265/N5K072F8.

Flato, G. M., and W. D. Hibler, 1995: Ridging and strength in modeling the thickness distribution of Arctic sea ice. J. Geophys. Res., 100, 18 611-18626, https://doi.org/10.1029/ 95JC02091.

Gelaro, R., and Coauthors, 2017: The Modern-Era Retrospective Analysis for Research and Applications, version 2 (MERRA-2). J. Climate, 30, 5419-5454, https://doi.org/10. 1175/JCLI-D-16-0758.1.

Granskog, M. A., A. Rösel, P. A. Dodd, D. Divine, S. Gerland, T. Martma, and M. J. Leng, 2017: Snow contribution to firstyear and second-year Arctic sea ice mass balance north of Svalbard. J. Geophys. Res. Oceans, 122, 2539-2549, https:// doi.org/10.1002/2016JC012398.

Hegyi, B. M., and P. C. Taylor, 2018: The unprecedented 2016-2017 Arctic sea ice growth season: The crucial role of atmospheric rivers and longwave fluxes. Geophys. Res. Lett., 45, 5204-5212, https://doi.org/10.1029/2017GL076717.

Herron, M. M., and C. C. Langway, 1980: Firn densification: An empirical model. J. Glaciol., 25, 373-385, https://doi.org/10. 1017/S0022143000015239.

Hersbach, H., and Coauthors, 2020: The ERA5 global reanalysis. Quart. J. Roy. Meteor. Soc., 146, 1999-2049, https://doi.org/10. 1002/qj.3803.

Hezel, P. J., X. Zhang, C. M. Bitz, B. P. Kelly, and F. Massonnet, 2012: Projected decline in spring snow depth on Arctic sea ice caused by progressively later autumn open ocean freezeup this century. Geophys. Res. Lett., 39, L17505, https://doi. org/10.1029/2012GL052794.

Hunke, E. C., W. H. Lipscomb, A. K. Turner, N. Jeffery, and S. Elliott, 2015: CICE: The Los Alamos Sea Ice Model documentation and software user's manual version 5.1. Los Alamos National Laboratory Doc. LA-CC-06-012, 116 pp.

Jakobson, L., T. Vihma, and E. Jakobson, 2019: Relationships between sea ice concentration and wind speed over the Arctic Ocean during 1979-2015. J. Climate, 32, 7783-7796, https://doi.org/10.1175/JCLI-D-19-0271.1.

Kim, K. Y., J. Y. Kim, J. Kim, S. Yeo, H. Na, B. D. Hamlington, and R. R. Leben, 2019: Vertical feedback mechanism of winter Arctic amplification and sea ice loss. Sci. Rep., 9, 1184, https://doi.org/10.1038/s41598-018-38109-x.

Kobayashi, S., and Coauthors, 2015: The JRA-55 reanalysis: General specifications and basic characteristics. J. Meteor. Soc. Japan, 93, 5-48, https://doi.org/10.2151/jmsj.2015-001.
Kwok, R., S. Kacimi, M. A. Webster, N. T. Kurtz, and A. A. Petty, 2020: Arctic snow depth and sea ice thickness from ICESat-2 and CryoSat-2 freeboards: A first examination. J. Geophys. Res. Oceans, 125, https://doi.org/10.1029/2019JC016008.

Letterly, A., J. Key, and Y. Liu, 2016: The influence of winter cloud on summer sea ice in the Arctic, 1983-2013. J. Geophys. Res. Atmos., 121, 2178-2187, https://doi.org/10.1002/ 2015JD024316.

Lindsay, R., and A. Schweiger, 2015: Arctic sea ice thickness loss determined using subsurface, aircraft, and satellite observations. Cryosphere, 9, 269-283, https://doi.org/10.5194/tc-9-2692015.

—, M. Wensnahan, A. Schweiger, and J. Zhang, 2014: Evaluation of seven different atmospheric reanalysis products in the Arctic. J. Climate, 27, 2588-2606, https://doi.org/10.1175/JCLID-13-00014.1.

Liu, Y., and J. R. Key, 2014: Less winter cloud aids summer 2013 Arctic sea ice return from 2012 minimum. Environ. Res. Lett., 9, 044002, https://doi.org/10.1088/1748-9326/9/4/044002.

Maykut, G. A., 1978: Energy exchange over young sea ice in the central Arctic. J. Geophys. Res., 83, 3646, https://doi.org/10. 1029/JC083iC07p03646.

- 1982: Large-scale heat exchange and ice production in the central Arctic. J. Geophys. Res., 87, 7971-7984, https://doi. org/10.1029/JC087iC10p07971.

Merkouriadi, I., B. Cheng, R. M. Graham, A. Rösel, and M. A. Granskog, 2017: Critical role of snow on sea ice growth in the Atlantic sector of the Arctic Ocean. Geophys. Res. Lett., 44, 10 479-10 485, https://doi.org/10.1002/2017GL075494.

- G. E. Liston, R. M. Graham, and M. A. Granskog, 2020: Quantifying the potential for snow-ice formation in the Arctic Ocean. Geophys. Res. Lett., 47, e2019GL085020, https:// doi.org/10.1029/2019GL085020.

Park, H.-S., and A. L. Stewart, 2018: Dynamic and thermodynamic impacts of the winter Arctic Oscillation on summer sea ice extent. J. Climate, 31, 1483-1497, https://doi.org/10. 1175/JCLI-D-17-0067.1.

—, S. Lee, Y. Kosaka, S.-W. Son, and S.-W. Kim, 2015: The impact of Arctic winter infrared radiation on early summer sea ice. J. Climate, 28, 6281-6296, https://doi.org/10.1175/ JCLI-D-14-00773.1.

Peralta-Ferriz, C., and R. A. Woodgate, 2015: Seasonal and interannual variability of pan-Arctic surface mixed layer properties from 1979 to 2012 from hydrographic data, and the dominance of stratification for multiyear mixed layer depth shoaling. Prog. Oceanogr., 134, 19-53, https://doi.org/10.1016/ j.pocean.2014.12.005.

Persson, P. O. G., M. D. Shupe, D. K. Perovich, and A. Solomon, 2017: Linking atmospheric synoptic transport, cloud phase, surface energy fluxes, and sea-ice growth: Observations of midwinter SHEBA conditions. Climate Dyn., 49, 1341-1364, https://doi.org/10.1007/s00382-016-3383-1.

Petty, A. A., D. L. Feltham, and P. R. Holland, 2013: Impact of atmospheric forcing on Antarctic continental shelf water masses. J. Phys. Oceanogr., 43, 920-940, https://doi.org/10. 1175/JPO-D-12-0172.1.

—, M. M. Holland, D. A. Bailey, and N. T. Kurtz, 2018a: Warm Arctic, increased winter sea ice growth? Geophys. Res. Lett., 45, 12 922-12 930, https://doi.org/10.1029/2018GL079223.

— M. Webster, L. Boisvert, and T. Markus, 2018b: The NASA Eulerian Snow on Sea Ice Model (NESOSIM) v1.0: Initial model development and analysis. Geosci. Model Dev., 11, 4577-4602, https://doi.org/10.5194/gmd-11-4577-2018. 
Pomeroy, J. W., and L. Li, 2000: Prairie and Arctic areal snow cover mass balance using a blowing snow model. J. Geophys. Res., 105, 26619-26 634, https://doi.org/10.1029/2000JD900149.

_ , P. Marsh, and D. M. Gray, 1997: Application of a distributed blowing snow model to the Arctic. Hydrol. Process., 11, 1451-1464, https://doi.org/10.1002/(SICI)1099-1085(199709)11: $11<1451::$ AID-HYP449>3.0.CO;2-Q.

Ricker, R., S. Hendricks, F. Girard-Ardhuin, L. Kaleschke, C. Lique, X. Tian-Kunze, M. Nicolaus, and T. Krumpen, 2017: Satellite-observed drop of Arctic sea ice growth in winter 2015-2016. Geophys. Res. Lett., 44, 3236-3245, https://doi.org/ 10.1002/2016GL072244.

Roberts, A. F., E. C. Hunke, S. M. Kamal, W. H. Lipscomb, C. Horvat, and W. Maslowski, 2019: A variational method for sea ice ridging in Earth system models. J. Adv. Model. Earth Syst., 11, 771-805, https://doi.org/10.1029/2018MS001395.

Saha, S., and Coauthors, 2014: The NCEP Climate Forecast System version 2. J. Climate, 27, 2185-2208, https://doi.org/10. 1175/JCLI-D-12-00823.1.

Semtner, A. J., 1976: A model for the thermodynamic growth of sea ice in numerical investigations of climate. J. Phys. Oceanogr., 6, 379-389, https://doi.org/10.1175/1520-0485(1976)006 $<0379$ :AMFTTG $>2.0 . \mathrm{CO} ; 2$.

Smith, R., and Coauthors, 2010: The Parallel Ocean Program (POP) reference manual. Los Alamos National Laboratory Tech. Rep. LAUR-10-01853, 140 pp.

Steele, M., R. Morley, and W. Ermold, 2001: PHC: A global ocean hydrography with a high-quality Arctic Ocean. J. Climate, 14, 2079-2087, https://doi.org/10.1175/1520-0442(2001) 014<2079:PAGOHW >2.0.CO;2.

Storto, A., and S. Masina, 2016: C-GLORSv5: An improved multipurpose global ocean eddy-permitting physical reanalysis. Earth Syst. Sci. Data, 8, 679-696, https://doi.org/10.5194/essd8-679-2016.

Stroeve, J. C., D. Schroder, M. Tsamados, and D. Feltham, 2018: Warm winter, thin ice? Cryosphere, 12, 1791-1809, https://doi. org/10.5194/tc-12-1791-2018.

Sturm, M., and S. Stuefer, 2013: Wind-blown flux rates derived from drifts at Arctic snow fences. J. Glaciol., 59, 21-34, https://doi.org/10.3189/2013JoG12J110.

- H. Hon, and D. K. Perovich, 2002: Winter snow cover on the sea ice of the Arctic Ocean at the Surface Heat Budget of the Arctic Ocean (SHEBA): Temporal evolution and spatial variability. J. Geophys. Res., 107, 8047, https://doi.org/10.1029/ 2000JC000400.

Tsamados, M., D. L. Feltham, and A. V. Wilchinsky, 2013: Impact of a new anisotropic rheology on simulations of Arctic sea ice. J. Geophys. Res. Oceans, 118, 91-107, https://doi.org/10. 1029/2012JC007990.
Tsujino, H., and Coauthors, 2018: JRA-55 based surface dataset for driving ocean-sea-ice models (JRA55-do). Ocean Modell., 130, 79-139, https://doi.org/10.1016/j.ocemod.2018.07.002.

Turner, A. K., E. C. Hunke, and C. M. Bitz, 2013: Two modes of sea-ice gravity drainage: A parameterization for large-scale modeling. J. Geophys. Res. Oceans, 118, 2279-2294, https:// doi.org/10.1002/jgrc.20171.

Vihma, T., and Coauthors, 2016: The atmospheric role in the Arctic water cycle: A review on processes, past and future changes, and their impacts. J. Geophys. Res. Biogeosci., 121, 586-620, https://doi.org/10.1002/2015JG003132.

Warren, S., I. Rigor, N. Untersteiner, V. F. Radionov, N. N. Bryazgin, Y. I. Aleksandrov, and R. Colony, 1999: Snow depth on Arctic sea ice. J. Climate, 12, 1814-1829, https://doi. org/10.1175/1520-0442(1999)012<1814:SDOASI > 2.0.CO;2.

Webster, M. A., and Coauthors, 2018: Snow in the changing seaice systems. Nat. Climate Change, 8, 946-953, https://doi.org/ 10.1038/s41558-018-0286-7.

— C. Parker, L. Boisvert, and R. Kwok, 2019: The role of cyclone activity in snow accumulation on Arctic sea ice. Nat. Commun., 10, 5285, https://doi.org/10.1038/s41467-019-13299-8.

—, A. K. DuVivier, M. M. Holland, and D. A. Bailey, 2021: Snow on Arctic sea ice in a warming climate as simulated in CESM. J. Geophys. Res. Ocean, 126, e2020JC016308, https:// doi.org/10.1029/2020JC016308.

Wilchinsky, A. V., and D. L. Feltham, 2006: Modelling the rheology of sea ice as a collection of diamond-shaped floes. $J$. Non-Newtonian Fluid Mech., 138, 22-32, https://doi.org/10. 1016/j.jnnfm.2006.05.001.

Williams, J., B. Tremblay, R. Newton, and R. Allard, 2016: Dynamic preconditioning of the minimum September sea-ice extent. J. Climate, 29, 5879-5891, https://doi.org/10.1175/JCLID-15-0515.1.

Woods, C., and R. Caballero, 2016: The role of moist intrusions in winter Arctic warming and sea ice decline. J. Climate, 29, 4473-4485, https://doi.org/10.1175/JCLI-D-15-0773.1.

,-- , and G. Svensson, 2013: Large-scale circulation associated with moisture intrusions into the Arctic during winter. Geophys. Res. Lett., 40, 4717-4721, https://doi.org/10.1002/grl. 50912.

Zhang, J., and D. A. Rothrock, 2003: Modeling global sea ice with a thickness and enthalpy distribution model in generalized curvilinear coordinates. Mon. Wea. Rev., 131, 845-861, https://doi.org/10.1175/1520-0493(2003)131<0845:MGSIWA > 2.0.CO;2.

Zib, B. J., X. Dong, B. Xi, A. Kennedy, B. J. Zib, X. Dong, B. Xi, and A. Kennedy, 2012: Evaluation and intercomparison of cloud fraction and radiative fluxes in recent reanalyses over the Arctic using BSRN surface observations. J. Climate, 25, 2291-2305, https://doi.org/10.1175/JCLI-D-11-00147.1. 